\title{
Angst vor dem Hai : John Singleton Copleys Kunst der kulturellen Verfeinerung
}

\author{
Gockel, Bettina
}

DOI: https://doi.org/10.1515/9783110432695-013

Posted at the Zurich Open Repository and Archive, University of Zurich ZORA URL: https://doi.org/10.5167/uzh-181225

Book Section

Published Version

Originally published at:

Gockel, Bettina (2017). Angst vor dem Hai : John Singleton Copleys Kunst der kulturellen Verfeinerung. In: Gockel, Bettina; Volmert, Miriam. Wahrnehmen, Speichern, Erinnern : Memoriale Praktiken und Theorien in den Bildkünsten, 1650 bis 1850. Berlin: De Gruyter, 247-283.

DOI: https://doi.org/10.1515/9783110432695-013 
Bettina Gockel und Miriam Volmert (Hrsg.)

\section{WAHRNEHMEN, SPEICHERN, ERINNERN}

Memoriale Praktiken und Theorien in den Bildkünsten 1650 bis 1850

DE GRUYTER 


$$
\text { (n) . . . . . . }
$$

Fritz Thyssen Stitiftung

$$
\because
$$

\section{INHALTSVERZEICHNIS}

Einführung 7

\section{ERINNERN UND GEDÄCHTNIS.}

\section{MEDIALITÄT UND MATERIALITÄT}

Katia Saporiti

Erinnerung und Repräsentation

\section{ORDNEN UND SICHTBARMACHEN.}

FRÜHNEUZEITLICHE WISSENSVERMITTLUNG IM UMBRUCH

ISBN 978-3-11-044072-0

e-ISBN (PDF) 978-3-11-043269-5

e-ISBN (EPUB) 978-3-11-043275-6

Library of Congress Cataloging-in-Publication Data

A CIP catalog record for this book has been applied for at the Library of Congress.

Bibliografische Information der Deutschen Nationalbibliothe

Die Deutsche Nationalbibliothek verzeichnet diese Publikation in der Deutschen Nationalbibliografie,

detaillierte bibliografische Daten sind im Internet über http://dnb.dnb.de abrufbar.

(C) 2018 Walter de Gruyter GmbH, Berlin/Boston

Übersetzung der Beiträge von Jan Blanc und Hanneke Grootenboer: Dagny Hildebrandt, Miriam Volmert Lektorat des englischen Beitrags: Keonaona Peterson

Einbandabbildungen (von links nach rechts):

1. Robert Hooke, Fischschuppen unter dem Mikroskop, Kupferstich, 1665 (Detail)

2. Daniel Berger nach Peter Ludwig Lütke, Kupferstich, um 1792 (Detail)

3. Brosche mit Augenminiatur, um 1800, Aquarell auf Elfenbein, mit Perlen und Diamanten

Satz: SatzBild GbR, Sabine Taube, Kieve

Druck und Bindung: DZA Druckerei zu Altenburg GmbH, Altenburg

Printed in Germany

@ Gedruckt auf säurefreiem Papier

www.degruyter.com
Andreas Gormans

Vergessene Bilder, erinnerte Metaphern

Mediengeschichtliche Kontinuitäten und Brüche zwischen memoria passionis

und encyclopédie

49

Lisa Oberli

Evidenz der Sinne in Robert Hookes Micrographia 76

Valeska von Rosen

Wissensordnung und Darstellungsmaximen in der Biografik, nach Vasari'

Giovanni Pietro Bellori in den 1660er-Jahren

\section{AUSWÄHLEN UND BILDEN.}

WISSENSVERARBEITUNG IM 18. JAHRHUNDERT

David Allan

Remembering Reading

The British Commonplace Book in the Long Eighteenth Century 
Jan Blanc

Willkürliches oder unwillkürliches Erinnern?

Praktiken und Debatten um das Entlehnen in den Künsten im Großbritannien

des 18. Jahrhunderts 155

Michael Thimann

Gedächtnis und Gefühl

Bilderbibeln im 18. Jahrhundert

169

\section{SEHEN UND VERKNÜPFEN.}

\section{KÜNSTIERISCHE REFLEXIONEN UND BILDÄSTHETIKEN DES ERINNERNS UM 1800}

Reinhard Wegner

Strategien visueller Erinnerung

Karl Philipp Moritz und das Bildgedächtnis

\section{Miriam Volmert}

"A picture in her hand"

Erinnerungsbilder und Souvenirformen in Faltfächern des 18. Jahrhunderts

Hanneke Grootenboer

Wie man einen Kuss verwahrt

Die Porträtminiatur als intimes Andenken

Patrizia Munforte

Transcripts of features and forms ever at hand

Miniaturen in der nordamerikanischen Memorialkultur nach 1800

\section{ERINNERN UND GEGENWART.}

HISTORIENBILDER IM ZEICHEN VON TRANSNATIONALITÄT UND TRANSKULTURALITÄT

Bettina Gockel

Angst vor dem Hai

John Singleton Copleys Kunst der kulturellen Verfeinerung $\quad 247$
Miriam Volmert

\section{EINEÜHRUNG}

Eine Visitenkarte aus dem 18. Jahrhundert, die sich heute in der Beinecke Library befindet, zeigt eine grafische Ansicht, die zeitgenössische Bildthemen der europäischen Grand Tour aufnimmt (Abb. 1): In einer antikisierenden Ruinenlandschaft, in deren Hintergxund vage der Herkulestempel des römischen Forum Boarium auszumachen ist, haben sich zwei Männer vor einem gewaltigen Baufragment eingefunden. In Reisekleidung, begleitet von einem Hund, ziehen sie augenscheinlich eine Karte oder ein Buch für ihre Betrachtungen heran. Sie erinnern an die ab der Mitte des 18. Jahrhunderts aufkommenden Gruppendarstellungen von Grand-Touristen, wie sie etwa von Malern wie Nathaniel Dance angefertigt wurden. ${ }^{1}$ Vertieft sind die beiden den Überresten eines am Boden liegenden Steingebälks zugewandt, das sich in seinen brüchigen Formen, den nahsichtigen Ausmaßen wie auch in seiner Ausstattung deutlich von den dahinter zu sehenden Gebäuden abhebt. So sticht vor allem eine große Marmortafel ins Auge, die nicht allein in ihrer seitlichen Platzierung im ansonsten von mit floralem Dekor verzierten Gebälk buchstäblich aus dem Rahmen fällt. In geschwungener Handschrift ist hier ein Name zu lesen: "Col. Cosmo Gordon..2

Die offenbar in Massenfertigung gedruckte Visitenkarte bietet mit dem architektonischen Element der weißen Tafel ein leeres Feld, auf dem potenzielle Besitzer ihren Namen eintragen können. Es existierten etliche solcher ,Grand-Tour-Visitenkarten', in denen in der Bildtradition der Grand Tour etablierte Motive wie der Vesuvausbruch, das Kolosseum oder das Forum Romanum zur Kulisse für ein bisweilen als helles Steinfragment angelegtes, manchmal aber auch ganz abstrakt hineinragendes Namensfeld werden. ${ }^{3}$ Die im 18. Jahrhundert bereits konventionalisierten Formen der personalisierten

1 Vgl. zum Beispiel Nathaniel Dance, James Grant of Grant, John Mrtton, the Hon. Thomas Robinson and Thomas Wynne, ca. 1760, Öl auf Leinwand, $98,1 \times 123,8 \mathrm{~cm}$. Yale Center for British Art, New Haven, Inv.-Nr. B1976.7.19; siehe auch Anton von Maron, Zwei Reisende vor dem Konstantinsbogen in Rom, 1767, Öl auf Leinwand, $137 \times 101 \mathrm{~cm}$, Privatsammlung.

2 Es könnte sich bei Cosmo Gordon um den Sohn von William Gordon, 2nd Earl of Aberdeen, und Anne Gordon handeln. Er wurde in den 1730er-Jahren geboren und verstarb nach 1786. Vgl den kurzen biografischen Eintrag in I. S. Ersch und J. G. Gruber (Hg.), Allgemeine Encyklopädie der Wissenschaften und Künste [...], Erste Section, A-G, Leipzig 1862, S. 342

3 Siehe die Sammlung von Grand-Tour-Visitenkarten in der James Marshall and Marie-Louise Osborn Collection, Beinecke Rare Book and Manuscript Library, Yale University, Sign. Osborn c529.
Bildtafeln 295

Personenregister 


\section{ANGST VOR DEM HAI}

\section{John Singleton Copleys Kunst der kulturellen Verfeinerung}

"Me? Scared? Think of a time in your life when you were very brave in a frightening situation. [...]"

The ocean remains. You cannot pump this dry; and as long as it continues in its present bed so long all the causes which weaken authority by distance will continue.

„Die amerikanische Montage ist organisch-aktiv. Es ist falsch, ihr den Vorwurf zu machen, sich der Erzählung untergeordnet zu haben; im Gegenteil leitet sich das Erzählerische

"Wer hat für die Freiheit gearbeitet?"*

\section{Plädoyer in zweifacher Hinsicht}

Der vorliegende Beitrag plädiert aus historiografischen, methodologischen sowie theoretischen Gründen sowohl im Bewusstsein um den Forschungsstand als auch in Kenntnis des heutigen ,Zeitgeistes' für eine präzisierte historische Verortung und aktuelle Aneignung insbesondere von Copleys Gemälde Watson and the Shark aus dem Jahr 1778, das heute in der National Gallery of Art in Washington, DC, beherbergt wird (Taf. LXIX). ${ }^{5}$

1 Museumspädagogisches Programm für Kinder zu Copleys Gemälde Watson and the Shark in der National Gallery of Art, Washington, DC, siehe das Konzept der National Gallery of Art im Interne unter https://www.nga.gov/kids/watson/watsonactivity.htm (lettler Zugrf am 23. Jull 2017).

2 Edmund Burke, Speech on Concilation wits Amp Liberty, and Reform. Speeches and Letters. Edmund Burke, New Haven/London 200, S. 62-134,
hier S. 93 .

Gilles Deleuze, Das Bewegungs-Bild. Kino 1, übers, von Uirich Christians und Ulrike Bokelmann, durchges, von Karsten Witte, 7. Auflage, Limage. von Kasten Witte, 7. A. 52.

Wrearbeitet, in: $F A Z$, 5. 7. 2017, Nr. 153, S. N3.

5 Die Autoin ist Kolleginnen und Kollegen, die mündlich und schriftlich auf Vorträge zum Thema reagiert haben in Dank verbunden. An dieser Stelle danke ich vor allem für Vortragseinladungen, die wichtice Denkanstöße lieferten, darunter u. a. die Tagung Aufklärung als Prozess", Stiftung Lucerna Luzern 2016; der internationale Workshop zum Projekt "Handwörterbuch der antiken Sklaverei" (HAS) Klassisch-Philologisches Seminar, Universität Zürich, 2013; die Tagung Methoden der Auftë̈rung Ordnungsmuster der Wissensvermittlung und Erkenntnisgenerierung in Literatur und Kunst" des Graduiertenkollegs im Exzellenznetzwerk "Aufklärung - Religion Wissen. Transformationen des Religiösen und des Rationalen in der Moderne", Martin-LutherUniversität Halle (Saale), 2011; eine Vortragseinladung an der Université de Genève (Actualité de la Recherche), 2010; eine Vortragseinladung der Forschungsgruppe „Picture Act and Embodiment", 
In der Argumentation, im Konzept sowie der Sprachführung wird dementsprechend gleichsam wie in einem Plädoyer ein offensiver Schreibstil in der Bewegung zwischen Pro und Contra, zwischen Fragen und Antworten, zwischen Erkenntrissen und Kritik bevorzugt. Die Gründe für diesen Ansatz sind a) die Tatsache, dass Copleys Bild eine ungewöhnlich lange, transnationale historiografische Auseinandersetzung entfacht hat, b) dass seine Kernkomposition Aktualisierungen erfahren hat, die ein humanistisches, durchaus auch problematisches Pathos erkennen lassen, und c) dass die visuelle und narrative Überzeugungsstrategie des Bildes dazu provoziert, sich zeitgenössische Denkund Handlungsstrategien klarzumachen, die in multimedialen, performativen Bildern und deren Bild-Betrachter-Beziehungen implementiert sind.

\section{Edgar Winds wissenschaftliches ,Denkmal' für Copley}

Edgar Wind (1900-1971) hat 1938 in seinem Aufsatz "The Revolution of History Painting" dem amerikanischen Maler John Singleton Copley (1738-1815) ein wissenschaftliches Denkmal gesetzt. ${ }^{6}$ Er attestierte ihm, mit seinen Gemälden eine neue Form der Historienmalerei ins Leben gerufen zu haben, und es sei ihm daran gelegen gewesen, aktuelle Ereignisse im Rahmen der akademischen Gattung zu formulieren. Bis dahin hätten sich die Bildkünste, insbesondere die Malerei, der Gegenwart und deren Erinnerung eher nicht zugewandt. ${ }^{7}$ Wie sollten solche Bilder aussehen - das war eine brisante und zugleich prekäre Fragestellung, nicht zuletzt für einen Kunsthistoriker, der vor der Bedrohung des Nationalsozialistischen Regimes in Deutschland nach England geflohen

Humboldt-Universität zu Berlin, 2010; sowie die Einladung als Senior Advisor der Térra Foundation for American Art, Giverny, 2012. Zuerst entstand der Text für meine Antrittsvorlesung an der Universität Zürich im Frühjahr 2009 unter dem Titel "Kampf um kulturelle Verfeinerung. Di amerikanische Kunst des 17. und 18. Jahrhunderts". Meinen Kolleginnen und Kollegen am Kunsthistorischen Institut der Universität Zürich und der Philosophischen Fakultät, die Anregungen und Ermunterungen gegeben haben, danke ich von Herzen. Die kunsthistorisch umfassend die amerikanische Malerei betreffenden und die medientheoretischen sowie medienhistorischen Ausführungen des ursprünglichen Manuskripts aus dem Jahr 2009; die bis in die Filmgeschichte der Gegenwart reichen, werden in einer in Vorbereitung befindlichen Monografie unter dem Titel "Horror urch finden denn die vielen Jahre in ansen mich dankesworte werden sich ebenfalls in diesem viel wissenschaftlichen Austausch hervorgebracht dass im Runmehr schon begleitet, haben so ist, darauf angemessen einzugehen. Für die Redaktion und für die Abklärung der Bildrechte sowie für Literaturbeschaffung bin ich Miriam Volmert sowie Patrizia Mblatung der Bildrechte sowie zuletzt Victoria Fleury, studentische Assitentin an L Pall für Geschichte der bildenden Kich zuletzt Victoria

Siehe Edgar Wind, The Revolution of History Painting, in: Journal of the Warburg Institute 2 (Oktober 1938), Nr. 2, S. 116-127; zu Wind siehe Werner Busch, Heroisierte Porträts? Edgar Wind und und Philosoph, Berlin 1998, S. 33-48.

7 Siehe zur Konzeption von Malerei als dezidiert zeitgenössischer Kunst, die mit Verzeitlichung und sogar mit praktischer Aktualisierung, z. B. der Anpassung modischex Details im Portrait, arbeitet: Bettina Gockel, Kunst und Politik der Farbe. Gainsboroughs Portraitmalerei, Berlin 1999, siehe dort auch eine einleitende Diskussion über Edgar Wind. war und sich sicher überlegte, welche Bilder der Gegenwart die zerstörerischen historischen Exeignisse einfangen könnten - und welche Bilder gewissermaßen zu, Ikonen der Erinnerung', zu Gedächtnisikonen (nicht unbedingt zu nationalen Ikonen) würden werden können. Mit seinem Aufsatz unterstrich Wind überdies, dass ex Inhalt und Form eines Kunstwerks als eine vom Kunsthistoriker zu analysierende Einheit betrachtete, womit er sich gegen den Formalismus Heinrich Wölfflins wandte. ${ }^{8}$

Das uns heute auf den ersten Blick womöglich eher marginal erscheinende Gemälde und wohl kaum mehr beunruhigende Bild Watson and the Shark von John Singleton Copley ist aufgrund seiner Wirkmächtigkeit solch eine, Ikone' der Kunst des 18. Jahrhunderts geworden, ja bereits zur Entstehungszeit des Bildes war es eine solche, aber auch historiografisch kann dies für die transatlantische Forschung zur Kunstgeschichte geltend gemacht werden, und schließlich, allerdings sehr spät, erlangte das Gemälde den Status als eines der Hauptwerke der National Gallery of Art in Washington, DC. ${ }^{9}$ Eine De- und Rekontextualisierung scheint die dramatische Szene des Gemäldes in der heutigen Pressefotografie zur sogenannten Migrationskrise zu finden. Die im Boot in höchster Aufregung einen Rettungsversuch unternehmende Gruppe, ihre Anstrengungen und Handlungen sollen zusammen mit dem Haiangriff affektiv Angst auslösen, und sie thematisieren zugleich die emotionale Überwindung und Bewältigung des Schrecken im Zeichen von Mitmenschlichkeit - eine ganz allgemeine Formel, die in ihrer intensiven Wirkungsästhetik eine Aktualität erlangt hat, die gerade durch Intellektuelle und Wissenschaftler wegen der plakativen Art und Weise der Gestaltung im Verhältnis zum konkreten Problem kritisiert wird. ${ }^{10}$ Die moralisierende Bedeutung von Copleys Bild wird heute auf in Booten und im Wasser um ihr Leben ringende Flüchtlinge transferiert und dabei in eine politische Problemlage verschoben, in welcher beispielsweise die

8 Vgl. Pascal Griener, Edgar Wind und das Problem der Schule von Athen, in: Horst Bredekamp, Bernhard Buschendorf, Freia Hartung und John Michael Krois ( $\mathrm{Hg}$ ), Edgar Wind. Kunsthistoriker Bernhard Buschendorf, Freia Hartung
und Philosoph, Berlin 1998, S. 77-103.

9 Siehe die Präsenz und Inszenierung von Copleys Gemälde auf der Eröffnungsseite der Website der Siehe die Präsenz und Inszenierung von Copleys Gemälde auf der Eroffnungsseite der Website der
National Gallery of Art in Washington (es ist das zweite von insgesamt sechs Bildern, die Impressionen der Sammlung und der Architektur des Museums zeigen): https://www.nga.gov/content/ ngaweb/about.html (letzter Zugriff am 11. Juli 2017).

10 Siehe den Blogbeitrag von Tanya Sheehan, in dem sie explizit auf Copleys Gemälde eingeht und dann Alternativen zur plakativen Darstellung von Migration darlegt: "Although worlds apart compositionally, these photographs both employ traditional, art-historical devices to depict refugees mind the Christian tradition of the Pieta in which the Virgin Mary cradles the dead Christ in her arms. Ponomarev's photograph invokes canonical paintings of doomed vessels and their human arms. Ponomarev's phóograph' invokes canocal pais1) and John Singleton Copley's Watson and the Shark (1778). Neither photographer likely had these artworks in mind when they snapped the shutter. Rather, my point is that the media selects refugee photographs to solicit strong affective reshutter. Rather, my point is that the media selects refugee photographs to solicit strong affective re-
sponses and those selections are shaped by (often Western) visual traditions. The compassion, empathy, pity, fear, outrage, or sadness that such pictures stimulate in viewers can lead to any number of actions - from quiet recognition of the humanity and vulnerability of refugees, to louder, activist gestures in support of displaced persons around the world." URL: https://www.fotomuseum.ch/de/ explore/still-searching/articles/30077_refugee (letzter Zugriff am 21. Juli 2017) 
Genfer Flüchtlingskonvention wie überhaupt Rechte und Gesetze gedehnt oder umgangen werden. ${ }^{11}$ In jedem Fall hat Copleys Bild und seine Wirkungsgeschichte die Kriterien erfüllt, die Aleida Assmann für die Entstehung einer "Gedächtnisikone" aufgestellt hat. ${ }^{12}$ Es ist der in der kunsthistorischen Literatur so gut wie gar nicht thematisierte affektive Aspekt des Bildes, der den Ausgangspunkt der hier vorgestellten Überlegungen zu diversen Themen bildet, die Fragen der Bildlichkeit von Humanität und der ih zugrunde liegenden Dynamik von Konfliktbewältigung, Zivilisierung und Erinnerung aufwerfen. ${ }^{13}$ Es würde den folgenden, noch skizzenhaft angelegten Text überfrachten, wenn die gesamte Wissens- und Forschungsgeschichte zu Copley ausgebreitet werden würde - dies soll an anderer Stelle erfolgen. Für den Auftakt einer neuen Forschung über die ,Ikonen', die Copley geschaffen hat, soll zunächst festgehalten werden, dass Edgar Wind in äußerster Detailgenauigkeit das Umfeld, in dem die Werke des amerikanischen Künstlers entstanden, beschrieben hat und damit einen europäischen Bildungshorizont in Anschlag brachte, den sich Copley durch seine Grand Tour im Jahr 1774 angeeigne hatte. ${ }^{14}$ Die transatlantische Forschung hat in ihren Interpretationen von Copleys Kunstwerken daran angeknüpft und die schon bei Wind vorhandene enorme Detailkenntnis von Quellen und Kontexten bereichert, ohne bis vor Kurzem von der angeblichen Differenz zwischen dem amerikanischen und englischen Copley als einer fundamental ausgewechselten Identität des Malers absehen zu wollen. ${ }^{15}$ Doch das, was Wind erfasste -

11 Siehe zu einer Analyse und Kritik des Mitleiddiskurses, den Fotografien, Berichterstattung und Politik, allen voran Angela Merkels Bemerkung, dass ein Land, das nicht alle Flüchtlinge (unabhängig von ihrem gesetzlich bestimmten Status) aufnehme, nicht mehr ihr Land sei, herstellen: Dieter Prokop, Demokratie braucht keine Moralkeulen, in: FAZ, 24. 7. 2017, Nr. 169, Rubrik: Die Gegenwart, S. 6.

12 Aleida Assmann, Individuelles Bildgedächtnis und kollektive Erinnerung, aus: Website der Hein rich Böll Stiftung, 18. Mai 2009, URL: https://www.boell.de/de/demokratie/kulturaustausch-6769. html (letzter Zugriff am 21. Juli 2017).

13 Siehe zur Diskussion des Begriffs, Affekt' Isabella Augart, Anna Pawlak und Lars Zieke, Vorwor in: Anna Pawlak, Lars Zieke und Isabella Augart (Hg.), Ars - Visus - Affectus. Visuelle Kulturen des Affektiven in der Frühen Neuzeit, Berlin/Boston 2016, S. 7-17, v. a. S. 9-12.

14 Copleys Grand Tour führte ihn von Paris über Marseille mit weiteren Zwischenstationen nach Florenz (fünf Tage), Rom (drei Monate) und Neapel (ein Monat). Er wurde von einem englischen Künstler begleitet, der für Copley alle organisatorischen und logistischen Fragen klärte und darübe mehr als enerviert war. Die später übertragenen Tagebücher von George Carter sind in Privatbesitz und wurden von Emily Ballew Neff ausgewertet. Siehe Emily Ballew Neff, A Remembrance of What We Have Seen. Copley Takes the Grand Tour, in: Emily Ballew Neff und Kaylin H. Weber (Hg.) American Adversaries. West and Copley in a Transatlantic World (Ausst.-Kat. The Museum of Fin

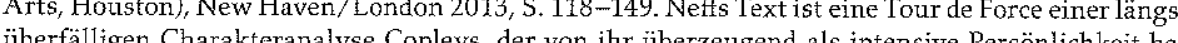

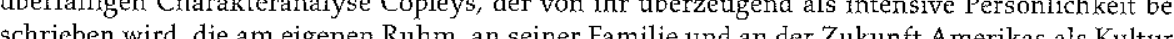
schrieben wird, die am eigenen R 15 Die Ausstellungen "John Singleton Copley in America" und "John Singleton Copley in England" hielWerkabschnitt fest; sie wollten jedoch dem Werk als Gesam theit insofern Rechnung englischen von amerikanischer Seite her vormals als dekadent beurteilte kiinstlerische Leistung Copleys in England net betrachtet wurde Gleichwohl schwingt nach wie vor eine nationale Ver Copleys das historisch Neue der Gemälde Copleys, ihr quasi-dokumentarischer Charakter, ihre außergewöhnlich reichhaltige Referenzierung, ihr kunst- und medientheoretisches Erneuerungspotenzial -, ist bis heute nicht auf einer theoretischen und methodischen Ebene weiter reflektiert und ausdifferenziert worden. Im Gegenteil, es ist festzuhalten, dass die medienhistorische Bedeutung des Gemäldes, wie sie im Warburg-Kreis methodisch erstmals adressiert worden ist, als Untersuchungsansatz keine Fortführung erlangt hat. Stattdessen hat sich die Forschung in nivellierender Weise darauf geeinigt, dass Copley ein moralisches und moralphilosophisches Thema behandele, welches letztlich in christlicher Ikonografie aufgehe. Das ist teilweise richtig, nur stellt sich darüber hinaus die Frage, welche Funktion und welche medienhistorischen und populären Auswirkungen dem Bild zu eigen sind - damals wie heute.

Winds bildungsmäßige, das heißt ikonologische (nicht allein ikonografische) Vernetzung der amerikanischen Erneuerer der Kunst, zu denen auch der Förderer und Konkurrent von Copley, Benjamin West (1738-1820), gehörte, mit den Größen der kontinentaleuropäischen Literatur ist aus seiner Sicht strategisch nachvollziehbar - Wind ging es um die Freilegung der "Denkzusammenhänge ${ }^{\prime \prime 16}$ in jener Zeit, aber auch um die kunsthistorisch belegbare Prolongierung und damit Vergegenwärtigung des Humanismusideals

Emily Ballew Neff (Hg.), John Singleton Copley in England (Ausst.-Kat. The National Gallery of Art Washington, The Museum of Fine Arts, Houston), London 1995; Carrie Rebora und Paul Staiti (Hg.), John Singleton Copley in America (Ausst.-Kat. Metropolitan Museum of Art, New York), New York 1995. Emily Ballew Neffs Forschungen zu Copley sind auch in dem neuesten Katalog über Copley und Benjamin West bestimmend, auf den im Detail weiter unten eingegangen wird, sieh Emily Ballew Neff und Kaylin H. Weber (Hg.), American Adversaries. West and Copley in a Transatlantic World (Ausst.-Kat. The Museum of Fine Arts, Houston), New Haven/London 2013. Copley hatte selbst zu der Splittung seines Lebenswerks in einen amerikanischen und einen englischen Part beigetragen, als er den amerikarischen Unverstand gegenüber den bildenden Künsten beklagte, eine Einschätzung, die wiederum dem Diskurs in seinem Heimatland, er sei eher ein fleißiger Arbeiter als ein genialer Maler, entgegengesetzt war und sein Talent für die englischen Rezipienten umso erstaunlicher erscheinen lassen sollte; siehe dazu Emily Ballew Neff, Introduction. Copley's "Native" Realism and his English "Improvement", in: Ballew Neff 1995 (wie Anm. 15), S. 12-22, hier S. 16f. und S. 19. Sehr wichtig für Copleys Historiengemälde ist Neffs Beobachtung, dass Copley sich in den besonders von Reynolds bestimmten Diskurs über die zivilisatorische Bedeutung und Macht der Kunst in einer dynamischen, ökonomisierten Gesellschaft einfügen wollte, siehe ebd, S. 20. Dabei ging es Copley auch um sein Heimatland, denn er erhoffte sich eine blühende künstlerische Kultur Amerikas, die durch kulturellen Austausch zustände kame und die auf beiden Seiten des Atlantiks Zivilisierung anstatt Krieg und Isolation hervorbrache. Zivisierung durch Kun und Erziehung war also ein zentraler Gedanke für den Kunster Copley, d (siehe Ballew Neff 1995 Siege of Gibraltar (1783-1791) "a display or himanity "n An er die Theorien von Adam Smith ïber [wie Anm. 15], S. 41.). Es durrte when das Verhaltnis von Moral und Wire Akademiker rezipiert wirden, siche zu Adam. Gainsboroughs Druckgraphik im Licht von Adam Gockel, Bedeuths ökonomischer, moralphilosophischer und sinnesphysiologischer Theorie, in: Werner Busch Smiths okonomischer, mo. Optik und Farbe im 18 und frühen 19. Jahrhundert (Schriften des Historischen Kollegs. Kolloquien 67), München 2008, S. 101-131, v. a. S. 125ff. sowie Tcho Mbaimba Caulker, The African-British Long Eighteenth Century. An Analysis of African-British Treaties, Colonial Economics, and Anthropological Discourse, Lanham 2009, Kap. 3, S. 72.

16 Busch 1998 (wie Anm. 6), S. 36. 
im Angesicht des Faschismus. ${ }^{17}$ Methodisch bleibt der Ansatz fragwürdig, wenn den Malern etwa bescheinigt wird, sie hätten instinktiv die Dramentheorie Racines aufgegriffen. Edgar Wind legt die spekulative Art seiner umfassend gebildeten Gedankengänge offen und benennt sie direkt - als Intellektueller sich seiner Denkvorgänge Rechenschaft ablegend -, gleichwohl will er sie aber in der Architektur seiner Argumentation verankert wissen. Dies überzeugt nicht und verweist auf das eigentliche Manko, das bereit von vielen Kunsthistorikern bestätigt worden ist, die geradezu unentwegt diverse Interpretationen der Gemälde Copleys in diesen ,Denkzusammenhängen' erarbeitet haben Es ist sicherlich so, dass es auch in Zukunft neue Funde zu wichtigen Kunstwerken geben wird. Doch es bleibt die Frage bestehen, wie diese Werke methodisch und theoretisch zu erfassen sind und weshalb sie mitunter bis heute eine zentrale Position in der Forschung und in der Geschichte der Institutionen einnehmen. ${ }^{18}$

Die Alternative zu Winds wissenschaftlichem Ansatz, der in einer bestimmten kulturhistorischen Kleinteiligkeit mündet, besteht heute in der theoretischen und methodischen Reflexion über Kerngehalte und ästhetische Ansätze von Copleys Gemälden insofern sie als öffentliche mediale Bilder verstanden werden. Dabei wäre beispielsweise zu prüfen, inwieweit Watson and the Shark nicht nur eine neue Art des Historienbildes darstellt, sondern als modernes Horrorbild anzusehen wäre, ob der Maler also gleichsam eine neue Gattung propagiert hätte, die sich erst in der Filmgeschichte durchsetzen sollte. Überraschend genau folgt das Bild denn auch den in der aktuellen Literatur aufgestellten Kriterien zu diesem Medium und Genre. ${ }^{19}$ Die in diesen Untersuchungen virulenten statistischen, neurologischen und begriffsgeschichtlichen Ansätze und Ergebnisse wer-

17 Siehe Horst Bredekamp, Götterdämmerung des Neoplatonismus, in: Kritische Berichte 4 (1986) S. 39-48.

18 Siehe exemplarisch jüngere Forschungen über Copley, die das Neue und die Neuartigkeit seiner Kunst thematisieren und dafür u. a. erzähltheoretische sowie Kulturtransfer und Interkulturalität betonende Ansätze wie auch die methodische Mythenbildung heranziehen und untersuchen: Jonathan Clancy, Human Agency and the Myth of Divine Salvation in Copley's Watson and the Shark, in: American Art 26 (2012), Nr. 1, S. 102-111; Holger Hoock, Empires of the Imagination: Politics, War, and the Arts in the British World, 1750-1850, London 2010; Harald Klinke, Amerikanische Historienmalerei. Neue Bilder für die Neue Welt, Göttingen 2011; Léa Kuhn, Das erste, amerikanische' Bitd.John Singleton Copley und die Anfangsinarrative nationaler Kunst, Zürich/Berlin 2013; Edward Larkin, The American School of Empire, Cambridge 2016; Jennifer L. Roberts, Failure to Deliver. Watson and the Shark and the Boston Tea Party, in: Art History 34 (2011), Nr. 4, S. 674-695. Besonders hervorzuheben ist, dass fast alle diese Publikationen, vor allem Roberts und Larkin, das Dynamische, Prozesshafte von Kultur und der in ihr wirksamen Kunst thematisieren. Die Interpretation des Einzelwerks als Spiegel historischer Ereignisse und eher statisches Werk erscheint betholt in Zeiten komplexer globaler Wissens- und Erfahrungstransfers.

Siehe hierzu u. a. Robert C. Solomon, Real Horror, in: Steven Jay Schneider und Daniel Shaw (Hg.), Dark Thoughts. Philosophic Reflections on Cinematic Horror, Lanham/Oxford 2003, S. 230-259. nischen Meton Copleys Gemalde Watson and the Shark weist zudem Strukturelemente einer orgaW. Griffith, beschrieben wum Aspelt beschreben hat; siehe hier Deleuze 2013 (wie Anm. 3), v.a. S. 52. Siehe andererseits digitalen Bildkunstwerken, weiter unten in diesem Beitrag sowie Anm. 21. den - im Übertrag auf ältere historische Bilder - die kunsthistorische Forschung nicht ersetzen oder fundamental korrigieren, aber adäquat interdisziplinär erweitern und in Bewegung versetzen. Denn die derzeitige Spannung zwischen der ikonografisch-ikonologischen Methode und den Vorbehalten, die die amerikanische Forschung gegenüber dieser Methodik entwickelt hat, führt zu einer positivistischen Prolongierung mikroskopischer Detailsuche und ideengeschichtlicher Kontexte.

Worin würden bildanalytische Ansätze bestehen, die konkret wären und sich nicht in quasi-philosophischen Konstruktionen ergehen würden? Ein gutes Beispiel für eine komparative Analyse bestünde darin, die digitalen Kreativkonstruktionen von Beate Gütschow mit Copleys Bildikonen zu vergleichen, ohne zwischen beiden eine Entwicklungs- und Fortschrittsgeschichte behaupten zu wollen. Copleys Gemälde sind im Prinzip nicht anders zusammengesetzt oder montiert als heutige digitale Bildkunstwerke, wie eben zum Beispiel diejenigen von Gütschow, die sich explizit auf das Studium der Landschafts- und Raumdarstellungen in der holländischen und englischen Malerei des 17. und 18. Jahrhunderts - ïbrigens auch direkt auf Thomas Gainsborough, dessen Werke Copley kannte ${ }^{20}$ - beruft. Ihre künstlerischen Äußerungen sind insofern erhellend, als sie angesichts der sich nie erfüllenden Wahrnehmung des Bildes als Reiz und Kippfigur die kunsthistorische Suche nach einer ikonografisch-ikonologischen oder narrativen Entschlüsselung als Quasiersatz der künstlerischen Verweigerung des Ganzheitlichen methodisch infrage stellen. Dabei geht es keinesfalls um eine Beliebigkeit der Aussage des Bildes, sondern um variantenreiche Verschiebungen der Wahrheit, die sich mit der räumlichen und mentalen Einstellung des Betrachters ereignen und zugleich dessen Heroisierung verweigern. Die Herausforderung zur Selbstaufklärung und die Bezweiflung der Bedeutung des subjektiven Betrachters führen zu einer gewollt prekären Ästhetik und Theorie des Bildes (oder sollte man von einer Ästhetik und Bildtheorie des Prekären sprechen?), die für die Moderne so nachhaltig geworden ist. Es ist auch diese künstlerische Sicht oder Stimme, die der vorliegende Aufsatz zu vermitteln versucht. ${ }^{21}$

20 Mit Gainsborough verbindet Copley darüber hinaus das Netzwerk von Gavin Hamilton, der für seinen Patron, William Petty, 2. Earl of Shelburne, tätig war, der 1784 den Titel Marquess of Lansdowne erhìelt. Shelburne gehörte zum Regiment von General Wolfe und unterstützte später die Friedensverhandlungen mit den nunmehr unabhängigen amerikanischen Kolonien. Er war schließlich auch vom Konzept des Freihandels überzeugt, das die kontroverse globale Wirtschaftspolitik bis heute nachhaltig pragt. Siehe zu Hamilton tund Shelburne Ballew Neff 2013a (wie Anm. 14), S. 133f. Siehe zu Shelburnes Rolle in den Friedensverhandlungen Grołbritanniens mit den abtrunnigen amerikanischen Kolonien C. R. Ritcheson, The Earl of Shelbourne and Peace with America, 1782-1783: Vision and Reality, in: The International History Review 5 (1983), Nr. 3, S. 322-345. Shelburne orientierte sich an David Humes Philosophie und vertrat liberale, radikale Ansichten, die ihn, so Ritcheson, eher als visionären Staatsmann auszeichnen, weniger als gewieften Parteipolitiker. Auf seinem Landsitz Bowood trafen sich Wissenschaftler, Phlosophen und Künstler zum gemeinsamen Austausch. Siehe Gockel 1999 (wie Anm. 7), Kap. III.2, besonders das Unterkapitel "Gainsborough und Priestley im Kreis englischer Reformpolitiker", S. 141ff

1 Gütschows Äußerungen erfolgten im Rahmen eines Künstlergesprächs an der Tagung "New Territories. Landscape Representation in Contemporary Photographic Practices (HU Berlin, Juni 2017). 


\section{Der US-amerikanische Präsident Barack Obama und die Partizipation} am Geschichtsbild der Zukunft

Am 24. September 2016 wurde in Washington, DC, an der Constitution Avenue ein imposantes Museum mit einer symbolischen Architektur eröffnet, das Smithsonian National Museum of African American History and Culture (Taf. LXX). Es handelt sich um einen Bau, der offenkundig einen Kopfschmuck der Ife nachahmt und sich damit auf einen kulturellen Bestandteil der Volkskunst Nigerias bezieht, ohne damit konkrete nationale Inhalte aufrufen zu wollen. ${ }^{22}$ Nigeria, ein Land, dessen Geschichte bis in die Zeit des alten Ägypten zurückreicht, bildete zusammen mit der Westküste Afrikas da Zentrum des transatlantischen Sklavenhandels, an dem die europäischen Kolonat mächte und afrikanische Machthaber beteiligt wan. Es wie europaischen Kolonialmächte und afrikanische Machthaber b der Architekten, viele Assoziationen mit dem Gebäude zu wecken und die Geschichte der Versklavung und Oppression von Millionen Afroamerikanern mit einer Optimismus ausstrahlenden Ästhetik des Schönen und Monumentalen geschickt zu verknüpfen. ${ }^{23}$

Zur Eröffnung dieses ersten Museums für afroamerikanische Geschichte, dessen Realisierung seit Beginn des 20. Jahrhunderts unter den wechselnden Regierungen der Vereinigten Staaten immer wieder The nie notwendige politische un Gerlangen konnte, hielt Barack Obama eine rhetorisch geschliffene politische Rede, in der er eine methodisch durchgreifend reflektierte Geschichtsschreibung forderte. ${ }^{24}$ Seine Gestik war dabei auffallend kontrolliert und zurückhaltend, so als wollte er, wie überhaupt während seiner achtjährigen Präsidentschaft, allzu symbolische, vor allem aber tradierte Gesten vermeiden zugunsten eines elaborierten, intellektuellen Diskurses, der allerdings womöglich nicht konsequent Abstand nimmt von den Konzepten von Naturalisierung, Nation und race als legitimierenden Bestandteilen von Geschichtsschreibung. ${ }^{2.5}$ In dieser Ambivalenz, die die Forschung über Obama

Vgl. auch Stefanie Gerke, Multiperspektivität als „symbolische Form”. Posthistoristische Strategien der Montage in Beate Gütschows S-Serie, in: Kunstchronik 70 (2017), Nr. Z, S. 336-344, va g38 340, Kap. "Fotomontage als Medienreflexion

2 lle-lfe ist eine legendare Gründungsstadt der Yoruba, einer Sprachgruppe, die nie einem einzigen Staat zugehörig war. Siehe als Vergleich zu dem Gebäude (Design: Freelon Group Adjem einzigen tes, Davis Brody Bond und SmithGroupIJR) einen Terracotta-Kopf, Höhe $16 \mathrm{~cm}$, National MusseumLagos, Nigeria, 79.R.6 (Ife 305)

23 Der Rückgriff auf die eindrückliche Ästhetik der Ife-Terracotta-Köpfe führt hinein in die Kontroverse über die Unabhängigkeit dieser Kultur, die heute als gesichert gilt. Der Anthropologe gesehene Afrikaforscher Leo Frobenius (1873-1938) hatte die Darstellungen noch auf eine griechische Kolonie zurückführen wollen, siehe https://africa.uima.uiowa.edtı/chapters/ancient-africa/ ife/?start=1 (letzter Zugriff am 22. Juli 2017).

Siehe die Rede auf dem Youtube-Channel The Obatna White House, URL: https://www.youtube $25 \mathrm{com} /$ watch? $\mathrm{Im}=\mathrm{xCh}$ Th 5 HO2SI (letzter Zugriff am 10. September 2017).

1m Kontrast zur zeichenhaften Gestik Donald Trumps beansprucht Obamas Gestik und Körperhaltung des ehem politische Bedeutung. Nichts wäre irrtümlicher, als die Lässigkeit und Zurückverstehen. Selbotverg̈̈ndichdenten der Vereinigten Staaten jenseits politischer Ikonologie zu hervorgehoben hat, trifft sich der Habitus des Politikers mit dem von Copley als einem inzwischen heroisierten, ersten großen amerikanischen Künstler, der sich alle Optionen amerikanischer Mythenbildung offenhielt, immer engagiert wirkte, ohne vom Moment affektiver Überzeugungsstrategie in seinem Werk und dem intensiven, persönlichen Streben nach Zugehörigkeit zum Establishment lassen zu können. Copley setzte seinerseits auf eine Doppelidentität als emotional engagierter Künstler mit "amerikanischem Herzen ${ }^{26}$ und als Gelehrter, der akademische Bildung und theoretisches Wissen für die zukünftige Verbesserungswürdigkeit seines Heimatlandes repräsentierte. Angesichts der Bedeutung Copleys heute - für das Narrativ der Nation und für transatlantische Studien gibt es keinen Imperativ des grammatischen Tempus, in dem man über ihn schreiben könnte - sind Vergangenheit, Gegenwart und Zukunft in der Forschung, Verbreitung und Vereinnahmung seines Werks allgegenwärtig. ${ }^{27}$

Das Museum ist - wie die Bilder Copleys - Medium erneuerbarer Geschichtsauffassung aus der Erfahrung der Gegenwart, ein museumswissenschaftlich innovativer Ansatz, der in einer Zeit der vermeintlichen Krisen der Museen die politische Bedeutung und Unabdingbarkeit dieser Institution nicht deutlicher machen könnte. So erhoffte sich Obama, das Nationalmuseum möge dazu beitragen, eine komplexere, umfassendere Geschichte Amerikas zu erzählen, als sie derzeit besteht. Nicht nur die Heldentaten und Paradigmenwechsel einer Nationengeschichte, wie sie im 19. und 20. Jahrhundert geschrieben wurden, sondern eine Geschichte, ja Geschichten - im Plural - von Millionen Menschen sollen die Nation stärken. Es ist dabei im allgemeinen Diskurs immer wieder von "black history”, vor allem von "Afro-Americans" die Rede, wobei die Sprachregelung nicht immer einheitlich ist, wenn allgemein Menschen mit afrikanischer Herkunft mit einbezogen werden. Das Projekt, die Partizipation der schwarzen Bevölkerung an der Geschichte Amerikas zu ermöglichen und historisch nachzuweisen, findet besonders im "Black History Month" seinen Ausdruck, einem Gedenkmonat, der in der 1926 eingeführten "National Negro History Week" seinen Ursprung hat ${ }^{28}$ - eine Formulierung, die heute sicher nicht mehr gewählt würde. In diese heikle Begriffsgeschichte sind

Herrschaft und Dominanz, die womöglich angesichts der Gesamtinszenierung besonders subtil wirken. Es ist sogar erhellend, sich vorzustellen, dass Obama die Theorie der zwei Körper des Herr schers umsetzt, nämlich als partikularer, physischer und als universeller, überzeitlicher Körper aufzutreten und wirkame Ausnahme - seines Lebens und seines Körpers. Und so argumentiert Obama oftmals nicht aus Grïnden. Von Rasse oder Nationalität als Beleg oder Topos der Substanz und gleichsam physischen terium der Politik wird eben nur schein bar Abstond genommen "Jens Kabisch, Biologichus KriNamen' - Barack Obama und die Hypostase des Market State, in: Dominik Finkeld, Juli In ohe und Michel Reder (Ho Normiertes Leben. Biopolitik und die Funktionalisierung ethischer Diskurse . Siehe unten, Anm. 36

27 Den Vernunftmenschen Copley rückt eine neue Biografie ins Licht: Jane Kamensky, A Revolution in Color. The World of John Singleton Copley, New York/London 2016.

Siehe http://www.history.com/topics/black-history/black-history-month (letzter Zugriff am 22. Juli 2017). 
Copleys Darstellungen von Schwarzen seit den ersten zeitgenössischen Kommentaren involviert.

Obama forderte nicht nur ein dominierendes, statisches Geschichtsbild heraus, sondern auch das Verständnis von Nation und Nationalität. Es ging ihm nicht allein darum, Schwarze beziehungsweise Afroamerikaner in der Geschichte Amerikas zu erinnern und dass diese Erinnerungen in dem neuen Museum gespeichert würden, sondern darum, dass deren Geschichten als wichtige, aktive Bestandteile der nationalen Geschichte verstanden werden. ${ }^{29}$ Er interessierte sich nicht so sehr für eine Geschichte, die Mitleid erregt, indem sie Leiden ausstellt, sondern für eine Geschichte von "Suffering and Delight ${ }^{\prime 30}$ - Leiden und Freude. Obama rief puritanische Werte auf, um Katharsis und Integration zu ermöglichen. ${ }^{31}$ Als Höhepunkt der Zeremonie präsentierte er ein Bild gelebter und lebendiger Geschichte, indem er eine Familie auftreten ließ, die mit ihm das Museum eröffnete und so ein Zeichen setzte gegen eine singulär männlich bestimmte Heldengeschichte. Zugleich reihte er sich in eine neue Forschungsrichtung ein, die Sklaven als politische Akteure ins Gedächtnis ruft, anstatt die Geschichte der Sklaverei als Heldengeschichte weißer Abolitionisten und Akteure zu erzählen. ${ }^{32}$

Eine fast hundertjährige Frau, Ruth Odom Bonner, stand quasi als natürliches Symbol unversehens - und für den Anspruch des Museums stellvertretend - im Mittelpunkt der Aufmerksamkeit: ihrerseits Patronin einer Familie, deren Biografien in die Zeit der

29 Die Pluralität von Geschichtsbildern, aber auch die Frage, wer das moralische Recht hat, daran mitzuschreiben, wird aktuell heftig anlässlich der Ausstellung der Whitney-Biennale diskutier. Siehe hierzu z. B. Andrea Kohler, Schwarzes Leid, weisser Blick, in: NZZ, 6. April 2017. Siehe auc die Diaspora-Forschung, u. a. von Tha Campl, u. a. Pextorming Stilness. Diaspora and Stasis in Black German Vernacular Fhotography, in: Qui Parle 26 (2017), Nr. 1, S. 155-170. Obama hat 2016 ein klares Zeichen für eine neuartige Geschichtsschreibung gesetzt, als er seine Sommerlektür kundtat - den Roman The Underground Railroad von Colson Whitehead. Siehe dazu die Rezension von Andreas Eckert, Wer hat für die Freiheit gearbeitet?, in: FAZ, 5. 7. 2017, Nr. 153, S. N3. Viele haben diesen Roman als Sinnbild aktueller Rassenkonflikte in den Vereinigten Staaten gelesen Bisłang dominiert die Vorstellung, weiße, besonders aufgeklärte Bürger und Politiker hätten , die' Menschenrechte für, ihre' schwarzen Brüder und Schwestern durchgesetzt. Schwarze Menschen als Akteure der Geschichte und Geschichtsschreibung werden für die erste Phase der Emanzipation kaum berücksichtigt, auch wenn es spektakuläre Ausnahmen gibt. Wie im Folgenden gezeigt werden soll, ist Copley der erste Künstler, der Geschichtsschreibung aus der Sicht schwarzer Menschen propagiert. Dass er dabei in einem loyalistischen Umfeld arbeitete, ist umso interessanter. Denn er war ein Küstler und kein Politiker; Copley wollte sein Talent zum Ausdruck bringen, Geld verdienen und sozial aufsteigen. Deshalb amalgamierte er aus den loyalistischen und abolitionistischen sich ihre Statur bis in die Filngeschichte des 20 , so schön, so unindividuell, so verführerisch, das funktioniert bis heute, sicher vornehmli coür 20 . Jahnunderts verfolgen lässt. Sein Erfolgstezep funken nicht auch fiir ein schwarzes Publikum wes im Zube der Büre gelten seine Bildschöpbeauty' durch Bilder konstruierte? Siehe dazu Deborah Willis, Posing Beouty: African Images from the 1890 s to the Present, New York 2009.

30 https://www.nytimes.com/2016/09/25/us/politics/obama-african-american-museum.html (letzter Zugriff am 26. Juni 2017).

31 Vgl. Brian H. Cosby, Suffering and Sovereignty. John Flavel and the Puritans on Afflictive Providence, Grand Rapids, MI, 2012

32 Siehe Manisha Sinha, The Slave's Cause. A History of Abolition, New Haven/London 2016.
Sklaverei zurückreichen und deren jüngstes Mitglied, Christine, ein Mädchen ist, dem die Zukunft in aller Freiheit zu Füßen liegen soll..$^{33}$ Der Siebenjährigen standen keine Tränen in den Augen, sondern sie konnte es kaum erwarten, diese - ihre - Zukunf quasi mit dem Museum zu eröffnen, und zog kräftig mit an dem Seil, mit dem die Glocke einer der ersten, 1776 von Afroamerikanern gegründeten Kirchen in Virginia geläutet wurde. Es war offenkundig, dass Obama so auch ein Zeichen für eine neue Genderpolitik innerhalb der ,Black History' setzen wollte, die lange Zeit von schwarzen Männern als Autoren und Akteuren dominiert wurde. ${ }^{34}$

Die Bühne mit Protagonisten dieser Art auszustatten - das erscheint wie ein Historienbild der Gegenwart und Zukunft, das Generationen umspannt. Wie wirkmächtig diese Inszenierung war, belegt die Resonanz in den Medien, wo es hieß, dieser Staatsakt habe der Gründung einer Nation geglichen. Obama verwendete in seiner historischen Rede den Begriff der Aufklärung und die Metapher des Lichts je einmal. Und in der Tat ist die Geschichte der Abschaffung der Sklaverei ohne den Prozess der Aufklärung nicht denkbar. Das Museum, so meinte er, solle für viele Generationen Licht in die komplexe Geschichte afroamerikanischer Menschen bringen. Seine Auffassung von der Funktion des Museums als Bildungsinstitution und als Speicher für Erinnerung, als Fundament von Geschichtsschreibung wie auch sein Rückgriff auf Prozessualität als Paradigma waren dabei traditionell in der Epoche der Aufklärung verankert. Er trug so auch der Einschätzung Rechnung, dass seine Präsidentschaft ohne den Abolitionismus der 1770er- und 1780er-Jahre beiderseits des Atlantiks nicht möglich gewesen wäre.

33 Die Familie Bonner und deren Geschichte soll zufällig einem Mitglied des Festkomitees des Museums aufgefallen sein. Wie die Washington Post am 25. September 2016 schrieb, war der Familie bis kurz vor der Zeremonie nicht klar, wie sehr sie im Mittelpunkt stehen würde: https://www. washingtonpost.com/news/arts-and-entertainment/wp/2016/09/25/descended-from-a-slavethis-family-helped-to-open-the-african-american-museum-with-obama/?utm_term=.7998 ddcd724d (letzter Zugriff am 22. Juli 2017). Der Vater von Ruth Bonner, Elija Odom, konnte aus der Sklaverei fliehen und wurde Mediziner und Inhaber einer Apotheke in Biscoe, Arkansas. Arkansas ist durch Lynchjustiz und Rassenunruhen bis in die 1950er-Jahre bekannt Aeworden. Der Bezug

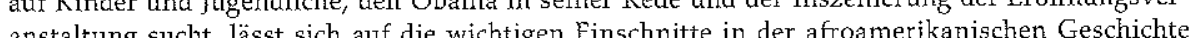

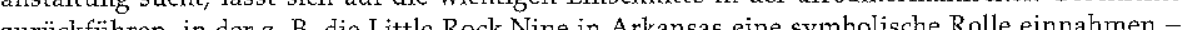
zurückulten, in der 2 . B. de Litte Ro Ner wolten und von einer militärischen Einheit geschïtzt werden mussten. Später erhielten sie Auswolten und von einer millthroct

34 Legendär für die Heroisierung des schwarzen Mannes ist der Protagonist Kunta Kinte in Alex Wer Roman und dessen nische Ceschichte in massenmedialer Aufmachungum und thematisierten erstmals afroanterikadie Metapher der Verwurzelung, die tiefer reiche als alle Bäume an der National Mall. In der Tat zeichnet sich das Museumsgebäude durch seine tief in die Frde reichenden Untergeschosse aus. Obama naturalisiert Geschichte, weil er suggeriert, die tiefe Grabung sei mit der Länge und Bedeutung afroamerikanischer Geschichte gleichzusetzen 


\section{Ein , amerikanisches Herz"?}

Wie sah die Konstellation von Erinnerung und Geschichte im 18. Jahrhundert aus? Ist versucht worden, so wie es Obama einfordert, Geschichtsschreibung als eine komplexe Angelegenheit der Praktiken und Ideen von Künstlern, Institutionen und Millionen beteiligter Individuen zu denken? Der Prozess, Aufklärung' bildet ein Klangbild aus allen diesen Komponenten. Womöglich wird es noch lange dauern, bis die in Disziplinen verhaftete Geschichtsschreibung in der Lage ist, historische Komplexität in ihrer Prozesshaftigkeit und Dynamik theoretisch und methodisch nachvollziehbar zu machen.

Im Folgenden wird von Überlegungen und Verbildlichungen zur jungen Nation Amerika im 18. Jahrhundert ausgegangen. Edmund Burke (1729-1797), Theoretike ästhetischer Theorien und politischer Autor, bezeichnete das amerikanische Volk in seiner klassisch gewordenen "Speech on Conciliation" (22. März 1775) als junge Nation, die noch hineinwachsen müsse in ein männliches Erwachsenendasein. Burke, der sich nur Männer als Leitfiguren vorstellen konnte und bis heute allzu vorschnell als konservativer Geist eingeschätzt wird, hatte eine sehr eigene intellektuelle Agenda, die ihn auch als Liberalen erscheinen lässt. ${ }^{35}$

Über Burke, den Old Whig, und seine facettenreichen Ansichten könnte sicher ausgiebig debattiert werden, aber er hat sich - daran besteht kein Zweifel - immer wieder für Minderheiten, Gerechtigkeit und offene Möglichkeiten in der Zukunft eingesetzt, während er zugleich ein Verfechter des Naturgesetzes war, - als solcher ist er in der modernen Geschichtsschreibung und in der postmodernen Theorie durchaus nachvollziehbar einer rigiden Kritik unterworfen worden, zumal er die Französische Revolution verurteilte; sie erschien ihm als Gewaltakt, die seinen Vorstellungen einer auf dem Naturrecht basierenden Gesellschaftsbildung nicht entsprach. Dieser Autor, der multiple politische Positionen im Prozess der sich zu seiner Lebenszeit überschlagenden Ereignisse in Europa und Amerika einnahm, wie auch immer man seine diversen Schriften beurteilen mag, entschärfte die Spannungen im Konflikt zwischen dem Mutterland Großbritannien und den abtrünnigen Kolonien, indem er von jungen Menschen sprach, einer jungen Nation, der man auch Fehler zugestehen müsse. Solch eine Jugendlichkeit der Nation und die Zustände des Unfertigen, der Unentschiedenheit, der Offenheit spielten für das Werk des Malers John Singleton Copley eine ebenso wichtige Rolle wie das Motiv der Angst und ihrer Überwindung, das in Burkes Rede rhetorisch prominent zum

35 Siehe Burke 2000 (wie Anm. 2), S. 79. Roger Stein, Copley's Watson and the Shark and Aesthetics in the 1770s, in: Calvin Israel (Hg.), Discoveries and Considerations: Essays on Early American Reprint von ebd. Gemälde und Burkes Ästhetik sowie dessen politischer Auffassung geschlagen; siehe bes. S. 116117. Burkes Metaphorik des Versinkens, Schmelzens und des Absterbens als natïrlicher Prozess de politischen Meinungs- und Positionsänderung müsste hinsichtlich der aqutischen Intoenierung Copleys weiter nachgegangen werden.
Einsatz kommt, um der Befürwortung einer Aussöhnung mit den aufständischen Untertanen im Sinne eines Akts der Zivilisierung, der Verfeinerung der eigenen Positionen Nachdruck zu verleihen.

Copley, der sich mit jugendlicher Allüre darstellte (Taf. LXXI), wird häufig als der erste wirklich amerikanische Künstler gefeiert, weil er ein unabhängiges, sehr umfassendes Werk schuf, das einerseits auf der traditionellen akademischen Kunsttheorie Europas beruht und andererseits zugleich äußerst originell und aktuell erscheint. Im Zuge der amerikanischen Unabhängigkeitsbestrebungen jedoch attestierte man ihm anlässlich der Rede des britischen Monarchen zur Anerkennung der Unabhängigkeit de amerikanischen Kolonien am 5. Dezember 1782 ein "amerikanisches Herz", obgleich er zu jener Zeit schon längst nicht mehr in Amerika lebte und auch nie mehr dahin zurückkehren sollte. ${ }^{36}$

Es sind drei Aspekte, die herausgegriffen werden, um zu zeigen, dass Copley Bildkonzepte entwarf, mit denen er das Historienbild nicht mehr als starres Exemplum und Erzählung einer kodifizierten Geschichte auffasste, sondern als dynamische, zeitgenössisch wirksame, unabgeschlossene und auch vom buchstäblichen Meinungsbild her nicht eindeutige Komposition, die aus dokumentarischen und fiktiven Elementen zusammengesetzt ist.

1. Copley bezieht den Betrachter als noch zu formendes Subjekt in den Handlungsraum seiner affektiv aufgeladenen Kompositionen ein, die häufig äußerst bewegt, wenn nich sogar schwungvoll und mitunter auch druckvoll zu nennen sind. Diese Charakterisierung trifft auf die Gemälde Watson and the Shark (R.A. 1778) ${ }^{37}$ und The Death of Major Peirson (1782-84) ${ }^{38}$ (Taf. LXXVIII), die hier erörtert werden, zu.

2. Copley entwirft konflikthafte Entscheidungssituationen, die bei der Bildbetrachtung eine Partizipation, eine Interaktion mit dem dargestellten Geschehen provozieren. Solch eine offene Situation wird durch die montageartige Darstellungsweise forciert. Der

36 Die Äußerung ist von Elkanah Watson (1758-1842) überliefert, der über sein Leben Tagebuch führte. 1782 malte Copley Watson (Öl auf Leinwand, $149 \times 121 \mathrm{~cm}$, Princeton University Art Museum, siehe: http://artmuseum.princeton.edu/collections/objects/29121 (letzter Zugriff am 8. Juhi 2017), beiden Legenden zut ge soin: Copley soll noch auf die offizielle Bestätigung der Unhängigen Kolonien dargestellt worden sein, Copley soln och auf die oll vielle Bestatigung der UnSiehe Jeremy Dupertuis Bangs, The Travels of Elkanah Watson. An American Businessman in the Sehe Jeremy Dur 1780 s Europe and in the Formative Decades of the United States, Jefferson, NC, 2015 S. 103 Vgl. Holger Hoock Empires of the Imarination. Politics, War, and the Arts in the British (1750-1850, Lom

Siehe Ballew Neff 1995 (wie Anm. 15), Kat.-Nr. 4; Jules David Prown, John Singleton Copley, Bd. 2: In England, 1774-1815, published for the National Gallery of Art, Washington, Cambridge, MA, 1966, S. 459-461.

38 Siehe Ballew Neff 1995 (wie Anm. 15), Kat.-Nr. 18; Prown 1966 (wie Anm. 37), S. 440-443. 
Betrachter wird geradezu aufgefordert, sich die Geschichte gleichsam selbst zusammenzubauen, selbst zu entscheiden, welche Facette des Dargestellten im Mittelpunkt steht.

3. Copley stellt den Typus des Nationalhelden infrage und offeriert neue Helden oder auch multiple Heldenhaftigkeit, besonders indem er in den genannten beiden Gemälden jeweils einen schwarzen Helden auftreten lässt, der weißen Protagonisten hilft bzw. diese rächt oder verteidigt. Er greift jeweils an zentraler Stelle in das Geschehen ein. Schwarze als Handlungsträger und moralische Leitfiguren darzustellen ist eine höchst ungewöhnliche Konstellation zu einer Zeit, in der die Befürwortung der Abschaffung der Sklaverei ein heftig umkämpftes Thema sowohl in Amerika wie in Europa war, mit dem zahlreiche, auch juristische Auseinandersetzungen einhergingen. Es ist, als würde Copley seinen Finger in die Wunde der Unabhängigkeitserklärung und der darin proklamierten Menschenrechte legen, die vom seinerzeit geltenden Recht her einen großen Teil der amerikanischen Bevölkerung ausschlossen.

Insgesamt - so die These - erfüllen Copleys komplexe, auf den individuellen Betrachter ausgerichtete Geschichtsdarstellungen die Forderungen von Barack Obama nach einer umfassenden, ausgreifenden Geschichtsschreibung wie auch nach einer aktiven, subjektiven Partizipation am Geschichtsbild der Zukunft und am Verständnis der eigenen Geschichte. Es ist diese überzeitlich angelegte, auf Involvierung und affektive Ansprache ausgerichtete Konzeption, der Copleys Bilder ihre intensive Wirkung auch jenseits der spezifischen historischen Ereignisse verdanken und die sie in neuen Kontexten aktuell erscheinen lässt, in denen es um Konflikte, Menschenrechte, Gemeinschaftsbildung und um politische Fragen der Zugehörigkeit in Zeiten des Übergangs und der globalen Mobilität geht.

\section{Watson and the Shark - Nationalepischer Nervenkitzel als Erfahrung} von "repeated injuries" und "future security

Mit dem großformatigen Gemälde Watson and the Shark (Taf. LXIX) erlangte Copley gleich nach der Ausstellung des Gemäldes im Jahr 1778 die Aufnahme als Vollmitglied in die Londoner Royal Academy of Arts, nachdem er bereits während seiner Zeit in Boston mit dem Porträt A Boy with a Flying Squirrel (1765) den Kontakt zu jener ehrwürdigen, 1768 gegründeten Kunstakademie gesucht hatte. ${ }^{39}$ Copleys Mitgliedschaft in der Royal Academy of Arts ging Hand in Hand mit seinem Streben nach kommerziellem Erfolg auf dem sich Mitte des 18. Jahrhunderts entwickelnden freien Kunstmarkt. Doch

39 Siehe dazu besonders Jennifer Roberts, Transporting Visions. The Movement of Images in Early America, Berkeley/Los Angeles/London 2014, hier Kap. 1, "Dilemmas of Delivery in Copley's Atlantic", S. 13-67. Roberts stellt überzeugend die künstlerische Kontinuität zwischen Copleys früheren Porträts und Watson and the Shark heraus. nicht das Gemälde, sondern die Nachstiche - im Fall von Watson and the Shark ein 1779 von Valentine Green angefertigtes Schabkunstblatt - sicherten dem Künstler seine Einnahmen, und tatsächlich konnte er mit Watson and the Shark einen finanziellen Erfolg verzeichnen, der ihn darin bestärkte, später selbst Ausstellungen zu organisieren und so das Publikum auf seine Bilder aufmerksam zu machen. ${ }^{40}$ Da auch die Royal Academy of Arts auf die Einnahmen aus den jährlichen Ausstellungen angewiesen war, geriet er in heftigen Konflikt mit dieser Institution, namentlich mit William Chambers, wobei er keine Ausnahme bildete, wenn man an die Auseinandersetzungen etwa von Thomas Gainsborough mit dem Hängungskomitee der Akademie und die selbstständigen Ausstellungen dieses Malers denkt. ${ }^{41}$

Von Copley ist überliefert, dass er im Sommer 1774 in London den im Bild als hilflos im Wasser treibender 14-jähriger Junge Dargestellten als längst erwachsenen und gewieften transatlantischen Protagonisten getroffen habe. Es war Brook Watson (1735-1807), der Copley auf das Jahrzehnte zurückliegende Schreckensereignis mit dem Hai aufmerksam machte. Die Idee zum Gemälde wird Copley mit auf seine Grand Tour genommen haben. Wie konnte er ein gesellschaftlich völlig unbedeutendes, allerdings spektakuläres, originelles Ereignis in ein Historienbild ummünzen? Dass Watson den

40 Copley hatte sich schon in seiner äußerst erfolgreichen Zeit als Porträtmaler in den Vereinigten Staaten nicht auf die gesellschaftliche Repräsentation eines Status quo beschränkt, sondern seiner Klientel eine Imagebildung offeriert, die fast nichts mit threr tatsächlichen sozialen, gesellschaftlichen und politischen Wirklichkeit, aber alles mit ihrem Selbstbild, ihren Ambitionen und Ansprüchen zu tun hatte, wie Paul Staiti gezeigt hat. Die Authentifizierung von Copleys künstlerischen Fiktionen erfolgte über die dann in England weiter vorangetriebene, fast gläsern zu nennende Malweise und montageartige Bildgestaltungen, die, wenn man sie genauer besieht, sogar offenlegen, dass es sich um Quasi-Dokumentationen handelt. Eben diese Mischung aus gelebter Geschichte, die seine Auftraggeber verkörperten, ihre fiktionale Aufladung in Copleys Gemälden verbunden mit seiner spezifisch unsentimentalen Malweise, ließ ihn für jene politischen Protagonisten besonders disponibel erscheinen, die sich neu, in die Zukunft eines unabhangigen Amerikas hineinerfinden wollten. Das Visionäre dieser Porträts übertrug Copley in seine Historiengemalde. Siehe Paul Staitis Ausfuhrungen zur Fiktion in Copleys amerikanischen Portrats, besonders am Beispiel der ausgezeichneten Analyse des Portrats von John Hancock, den Copley 1765 zu einer Zeit malte, al dieser politische Amter anstrebte (Hancock war Präsident des Kontinentalkongresses und erster Unterzeichner der Unabhängigkeitserklärung. Seine politischen Schachzüge, sein Charakter un sein Image als radikaler Patriot ließen ihn schon Lebzeiten zu einer schillernden Legende werden): Paul Staiti, Character and Class. The Portraits of John Singleton Copley, in: Marianne Doezema und Elizabeth Milroy (Hg.), Reading American Art, New Haven/London 1998, S. 12-37, hier S. 29-33. Statt Hancock in seiner Postur als modischen, Luxusgüter liebenden Gentleman zu zeigen, entwarf Copley das Imnage eines puritanischen, schmalbrüstigen Menschen, mit dem niemand Ausschweifungen, die Verachtung des Volks und den selbstsuichtigen Wechsel politischer Lager in Verbindung gebracht hätte: John Singleton Copley, John Hancock, 1765, Öl auf Leinwand, 124,8 $\times 100 \mathrm{~cm}, \mathrm{Mu}-$ seum of Fine Arts, Boston.

Die Aufnahme dieses Aufsatzes, der zuerst in dem Ausstellungskatalog John Singleton Copley in America (siehe oben, Anm. 15) erschien, in diese Anthologie, die die amerikanische Kunst vom 17. bis zum 20. Jahrhundert umfasst, belegt noch einmal die kanonische Bedeutung von Copley Werk für die amerikanische Kunstgeschichtsschreibung.

41. Vgl. u. a. Rosie Dias, "A World of Pictures": Pall Mall and the Topography of Display, 1780-99, in Miles Ogborn und Charles W. J. Withers (Hg.), Georgian Geographies: Essays on Space, Phac 
Maler mit dem Gemälde beauftragte, ist nicht belegt und sogar unwahrscheinlich, was in der neueren Literatur in der Regel bestätigt wird. Die Arbeit verblieb vielleicht in Copleys Besitz, obgleich auch das unsicher ist, weil der Künstler selbst eine Kopie malte, die er in seinem Atelier ausstellte. ${ }^{42}$ Es lässt sich folglich nur spekulieren, dass Watson eventuell später, als er sich in London stärker im öffentlichen Leben etabliert hatte, das Gemälde für seine Imagepflege nutzen wollte. Die frühe Provenienz des Gemäldes ist jedenfalls dunkel und verworren. Erst für das Jahr 1803 kann das in der Akademie ausgestellte Werk direkt mit Watson in Verbindung gebracht werden: Es ist das Jahr, in dem Watson am 5. Dezember zum Baronet erhoben wurde und damit fortan zur Gentry, dem niederen Adel, gehörte. Watson, der selbst früh verwaist bei seiner Tante und seinem Onkel aufwuchs, vermachte das Bild wahrscheinlich aus diesem Anlass einer Schule für verwaiste Knaben, als Exemplum für Mut, Tapferkeit und Erlösung und natürlich mit ihm selbst als großem Vorbild. Bis heute wird das Gemälde dementsprechend gern für museumspädagogische Aktivitäten mit Kindern und Jugendlichen eingesetzt. Zum Beispiel wird dem Geschehen in diversen Nachbildungen und -stellungen etwa durch eine Animation des Haimauls oder durch erschreckende Schreie eines Jungen ein besonderer Nervenkitzel verliehen, oder es wird dazu aufgefordert, eine Szene zu malen, in der man sehr große Angst hatte und diese zu überwinden vermochte:

"Me? Scared? Think of a time in your life when you were very brave in a frightening situation. Draw a frame on a piece of paper and sketch in the most exciting moment of your story. Where were you at the time? Was it day or night? Were you alone or with other people? What was you tell them how it all worked out? At the bottom of the picture frame draw a rectise, or will and in that space, write a few sentences to tell people about your bravery and yourgular box describe what you Jearned from the experiencess

Watsons Stiftung macht also bis heute das große, offenbar zeitlos pädagogische Potenzial des Gemäldes deutlich. Das Bild selbst verblieb einige Zeit im Christ's Hospital und geriet danach zunächst weitgehend in Vergessenheit. ${ }^{44}$ Erst 1857 wurde es wieder in der

42 Die drei Fassungen des Gemäldes bedürfen sicher einer neuen, eingehenden Untersuchung. Frap pierend ist, wie das Gemälde im Bostoner Museum of Fine Arts dem Original folgt, aber auch be genauem Hinsehen Abweichungen malerischer und motivischer Art zeigt. Die Bostoner Version wirkt malerisch hier und da etwas hingeworfen. Der Hai erscheint deutlich bedrohlicher und noch klarer als das Originalgemälde auf naturwissenschaftlichen Zeichnungen oder Modellen beruhend Wie hätte Copley eine so elaborierte Version der Zähne des Hais malen können, wenn er nicht direkt ein Modell oder eine Grafik vor Augen hatte? Warum hat er in der Kopie den Hai naturwissen43 Schaftlich genauer und oben, Anm. 1.

44 Die Provenienz wird von der National Gallery of Art wie folgt angegeben: „Brook Watson [17351807], London and East Sheen, Surrey; bequeathed to Christ's Hospital, London; [1] purchased 1963 by Nopley which repe Mr. Copley which repere be delivered to them immediately after the Decease of my Wife Helen Watson or before if hital to think proper so to do hoping the said worthy Covernors will receive he same as a testim she shall high estimation in which I hold that most Excellent Chaity and that they witl allow it to be hef einflussreichen "Art Treasures of the United Kingdom. Paintings by Modern Masters" in Manchester ausgestellt. Heute befindet sich Copleys Gemälde, wie erwähnt, in der Sammlung der National Gallery of Art in Washington, DC, wo es prominent mit einer fiir das Christ's Hospital angefertigten Inschriftentafel ausgestellt wird, auf der die Szene, die das Bild darstellt, zusammen mit der Lebensgeschichte von Watson als vorbildlich für die Erlangung privater und öffentlicher Tugend erzählt wird. ${ }^{45}$ Der Text dient vor allem der Nobilitierung Watsons und seiner Lebensstationen. Das Gemälde wurde 1963 durch die Stiftung von Ferdinand Lammot Belin (1881-1961) angekauft, seines Zeichens Diplomat, Regierungsbeauftragter unter Herbert Hoover, Philanthrop, Patriot und Gründungsmitglied der 1941 eröffneten National Gallery of Art. Eine hochformatige Version, die 1946 vom Detroit Institute of Art angekauft wurde, malte Copley 1782. Eine weitere Version im Boston Museum of Fine Arts, welche durch eine Schenkung im Jahr 1889 dorthin gelangte, dürfte die eigenhändige Kopie des Ausstellungsstücks sein, die in Copleys Familie kurzzeitig weitervererbt worden war, bevor sie auf den Kunstmarkt kam. So wie in der Washingtoner National Gallery of Art, so sind auch in Detroit und Boston Ankauf und Schenkung der Gemälde mit den Namen verdienter Politiker und Philanthropen verbunden. ${ }^{46}$

Die Forschung hat in der Nachfolge Edgar Winds immer wieder hervorgehoben, wie gerade amerikanische Künstler im 18. Jahrhundert das Historienbild zum Ereignisbild

in the Hall of their Hospital as holding out a most usefull Lesson to Youth.' (Public Record Office, London; copy, NGA curatorial file). The schoo's committee of almoners voted 28 September 1819 to accept the painting and place it in the great hall (munutes of a meeting of the Board of Almoners, Christ's Hospital, 28 September 1819; extract, NGA curatial file). The hospital was founded in London in 1553 and was moved to Horsham, Essex, in 1902; Encyclopaedia Britannica (11th ed., New York, 1910), 6: 295-296." Siehe: https://www.nga.gov/content/ngaweb/Collection/art-objectpage.46471.html\#provenance (1etzter Zugriff am 23. Juli 2017).

45 Der Text der Inschriftentafel lautet: "This picture representing a remarkable occurrence in the life of Brook Watson was bequeathed to the Royal Hospital of Christ in London by his will. He was of a very good family in the North of England but having lost both his parents early in life was brought up by an aunt, and before the age of fourteen years manifested a strong predilection for the sea, which led to the misfortune represented in the picture. He served in the Commissariat Department of the Army under the immortal Wolfe at Louisberg in 1758. In 1759 he was established as a merchant in London and was subsequently called upon to act as Commissary General to the Army in America commanded by Sir Guy Carleton, late Lord Dorchester. On his return from that service he was elected an Alderman of the City of London and one of its representatives in parliament, and continued Member of the House of Commons till he was appointed to the situation or Conmissary General to the Army under alden an Alderman of the City or London, Deputy Governor of the Bank of Englanl, \&c, \&e thus shewing that a tigh onsect. The picture was painted by John Singleton Copley Esq Royal Academician in the year 1778."

6 In Boston geht die Schenkung auf Maria Alice Appleton, die Ehefrau des 1 a a als Marineminister

46 In Boston geht die Schenkung auf Maria Alice Appleton, die Ehefrau des u. a. als Marineminister Ferry Jr. Fund Geöglicht Das Detroiter Bild kam vor 1786 durch Noël Desenfans auf den englischen Kunstmarkt. 
uminstrumentierten, indem sie Themen der Zeitgeschichte verbildlichten, so wie etwa Benjamin West den Tod des General Wolfe, 1770, auf der Folie der Beweinung Christi darstellte. Copleys Bild, für das ebenfalls zahlreiche christlich-ikonografische Quellen nachgewiesen wurden, ${ }^{47}$ stellt jedoch, wie erwähnt, kein zeithistorisch relevantes Ereignis, sondern eine Episode aus der Jugendzeit Brook Watsons dar, der als Schiffsjunge auf einem britischen Schoner im Hafenbecken von Havanna schwimmen ging, wo er von einem Hai dreimal angegriffen wurde. ${ }^{48}$ Von den ihm zur Hilfe eilenden Kameraden konnte er gerettet werden, sein rechtes Bein musste jedoch unterhalb des Knies amputiert werden; er erhielt eine Prothese, die auf zahlreichen, erheblich später entstandenen Karikaturen zu einer Art Markenzeichen für den im Jahr 1796 gewählten Bürgermeister von London wurde. ${ }^{49}$ Watson konnte sich in diesem Amt nicht halten. Zeitgenossen galt Watson als eher undurchsichtige, wenn nicht umstrittene Figur, sodass er gute Gründe dafür gehabt haben dürfte, im Christ's Hospital positive Meilensteine seines Lebens herausgestrichen zu sehen.

Copleys Gemälde wurde also, gänzlich unvorhergesehen, in verschiedene moralisierende, persönliche und nationale Diskurse eingebunden, in denen ein wichtiger Aspekt darin bestand, die dargestellte Szene eindeutig als Rettungsszene zu verstehen. Das Gemälde verweigert jedoch gerade die Darstellung einer glücklichen, erlösenden Rettung, obgleich in zeitgenössischen und späteren Bildbeschreibungen, wie etwa in den offiziellen Texten der National Gallery of Art, durchgängig zu lesen ist, das Bild stelle eben eine solche dar. ${ }^{50}$ Demgegenüber bleibt festzuhalten: Copley hat ein Geschehnis gemalt, welches selbst zu seiner Zeit für die Allgemeinheit nicht mehr relevant gewesen sein dürfte. Deshalb sind die akademische Anerkennung wie auch der Publikumserfolg

47 Besonders Werner Busch hat die Bedeutung der christlichen Ikonografie für Copleys Gemälde hervorgehoben. Siehe Werner Busch, Copley, West, and the Tradition of European High Art, in: Thomas W. Gaehtgens und Heinz Ickstadt (Hg.), American Icons. Transatlantic Perspectives on Eighteenth- and Nineteenth-Century American Art, Santa Monica, CA, 1992, S. 34-59.

48 Siehe in kurzer Zusammenfassung u.a. https://www.nga.gov/content/ngaweb/Collection/ highlights/highlight46471.html (letzter Zugriff am 12. September 2017) sowie Stein 1976 (wi Anm. 35), S. 87.

Siehe z. B. die Karikatur von Robert Dighton Jr, Sir Brook Watson, 1st Bt, 1803, handkolorierte Radierung, $31,6 \times 25,9 \mathrm{~cm}$, National Portrait Gallery, London, NPG D10764.

Zug. hlo Zuf 14 ïli der a second time, severing his right foot By the time Watson surfaced again his maged him unreached him. Copley depicts the boy's climatic rescue just as the sherk again, his mates had nearly a determined crewmate armed with a boat hook drove it away." Die narrative Vervoltutindigung dessen, was das Bild tatsächlich zeigt, ist offensichtlich, so als solten die Bruchstellen des Naretiven, die vielen offenen Fragen wie auch die Hybridität der Figuren überschrieben werden. Auredem wird angesichts der bildlichen Repräsentation von terror" " gesprochen, während Zeitgessen und Wissenschaftler im Zusammenhang dieses Bildes eher den Beoriff horror" verwenden Der dos Seil haltende Mann wird als "West African crewman" identifiziert. Die Forschung hat schon früb auf die Historizität und die Harmonisierungsstrategie dieses Begriffs hingewiesen. Siehe dozu Philip D. Curtin, Image of Africa. British Ideas and Action, 1780-1850, London 1965, S. 413. des Bildes erklärungsbedürftig. Worin, wenn nicht in der dargestellten Geschichte, lag die Bedeutung des Bildes für damalige Betrachter? Und worin besteht das Ereignis, welches das Gemälde für die amerikanische Kunst und Kultur bis heute so bedeutsam werden ließ?

Das Werk wurde zu einem Zeitpunkt ausgestellt, als die Auseinandersetzung zwischen England und den amerikanischen Kolonien in aller Munde war und dieses Thema die Londoner Pamphlete als Medien öffentlicher Meinungsbildung beherrschte. 1778 lag die amerikanische Unabhängigkeitserklärung zwei Jahre zurück, und das Britische Königreich sollte sich noch fünf Jahre im Krieg mit seinen überseeischen Untertanen befinden. In der Ausstellung der Royal Academy of Arts betrachteten in jenem Jahr täglich Hunderte von Besuchern Copleys Watson and the Shark und erfreuten sich womöglich an einem Schrecken, der so noch nie zuvor in einem Kunstwerk erfasst worden war starrten sie doch im unteren Drittel des Bildes in das weit aufgerissene Maul eines Hais, drohten sie doch selbst wie der weiße Jüngling in den fast über den unteren Bildrand zu schwappen scheinenden grünblauen bis bräunlichen Wellen den Halt zu verlieren, abzutauchen in einem uferlosen amorphen Element. ${ }^{51}$ Copley bietet nur einen Ankerpunkt die Seilschlinge im Wasser, die zu verfolgen er wie einen Ariadnefaden ausgelegt hat Dieses Seil, eine Rettungsleine, die als Linie durch das Gemälde geführt ist - sollte sie im übertragenen Sinn beim Betrachten ergriffen und gestrafft werden, sodass sie in der Hand des Verzweifelten zu liegen käme? Sollten Zeitgenossen, wenn sie aufblickten zu dem in Untersicht dargebotenen Gesicht des Seilträgers auf dem Boot, der Schlüsselfigur des Bildes - sollten sie am Ende das tun, was jener im Begriff ist zu tun, nämlich die Schlinge fest, entschlossen in die Hand nehmen, sodass der Jüngling zum rettenden Boot gezogen würde und die beiden Bootsjungen den seltsam transparenten Körper des Unglücklichen zu fassen bekämen? Wie auch immer das Angebot des Bildes in der Betrachtung aufgefasst werden mag: Copley stellte nicht nur ein Drama dar, sondern führte es als einen komplexen Prozess vor Augen, sodass der formalästhetische Eindruck von Bewegung und Dynamik einen rezeptionsästhetischen Effekt auslöste, der innere, gefühlsmäßige, ethische Aspekte implizierte und die Frage nach Rettung und Sicherheit auslöste.

Sollte es Copley womöglich gelungen sein, auf eine überraschend subtile Weise die in der Declaration of Independence gleich zu Beginn so eindrücklich beschriebenen Menschenrechte der "Safety and Happiness", der "future security" und sogar der "repeated 51 Copley lässt den Betrachter geradezu eintauchen in das Wasser, während z. B. Benjamin West in hington, DC, den Blick ouf das Wasser betont. Gleichwrohl nutzen beide Künstler die Dramatik und Emotionalität, die der unverstellte Anblick der See auslöst. Die Szenerie, die West entwirft, verteilt Spannung und Dramatik auf viele Figuren, Boote und Schiffe. Copley monumentalisiert dagegen Spannung und Dramatik auf viele Figuren, Boote und Schiffe. Copley monumentalisiert dagegen
und verleiht seinen Figuren so einen würdevollen Auftritt. Offensichtlich hatte sich West mit dem Werk The Battle of La Hogue für ein Entertainment entschieden, ganz im Unterschied zu seinem Gemälde The Death of General Wolfe. 
injuries ${ }^{452}$ im Rahmen eines an sich völlig unbedeutenden Ereignisses anklingen zu lassen? Die rhetorische Konfrontation zwischen britischer Barbarei und einer herbeigesehnten, civilized nation' mochte sich so manchem zeitgenössischen Betrachter vo Copleys Gemälde erschlossen haben, aber nicht als finales Statement oder klare Botschaft, sonders als offener, transnationaler, letztlich das Menschsein an sich betreffender Konflikt, zumal die amerikanischen Kolonien auf dem Feld der Barbarei nicht gerade unbedarft waren. ${ }^{53}$

Anstatt sich dem möglichen, soeben skizzierten konfliktreichen Drama auszusetzen und sich in dieses involvieren zu lassen, kann das Geschehen um die Haiattacke auch aus einer gebotenen Position der Sicherheit, mit innerer Distanz gesehen werden. Ein Schritt zurück vom Gemälde, und das Bildganze ließ sich erfassen, ohne sich auf die dargebotene Performanz des Horrors einzulassen. ${ }^{54}$ Die Involvierung in den Kampf um ein junges Menschenleben erscheint ohnehin vergeblich - oder etwa nicht? Die Frage nach einer emotionalen und vielleicht sogar ethischen Aktivierung beim Betrachten, ja auch nach der geradezu zwingend erscheinenden Interaktion zwischen dem seilwerfenden Bildakteur auf dem Boot und dem Rezipienten vor dem Werk sei vorerst beiseite gelegt, weil sie bislang in der Forschung nicht gestellt worden ist und es auf sie nicht ohne Weiteres eine Antwort gibt.

Wie stellt sich das Bild aus der ästhetischen Distanz dar? Copleys Komposition ist schichtweise, in drei Teilen aufgebaut, eine Konstellation, die in der Bildmitte von einer fast pyramidal aufgebauten Menschengruppe und den vergeblich nach dem Jungen ausgreifenden Bootsjungen in Weiß locker ineinander verzahnt wird (Taf. LXXII). Allerdings schließen sich weder diese Schichten des Bildes zu einem illusionistischen oder perspektivisch nachvollziehbaren Bildraum noch die einzelnen Elemente des Bildes - Schiffe, Boote, Wasser, Figuren - zu einem Ganzen zusammen. Geometrisch und stereometrisch wird das Verhältnis der zweidimensionalen Bildfläche zur suggerierten Räumlichkeit und die Plastizität der Figuren zum Raum ausgelotet. Die zentrale formale Dreieckskonstruktion ist nach rechts aus der Bildmitte verschoben, sodass sich die

52 Declaration of Independence (1776), in: John Grafton (Hg.), The Declaration of Independence and Other Great Documents of American History, 1775-1865, Mineola, NY, 2000, S. 7.

53 Es.liegt nahe zu formulieren, dass Copley den Ozean als Heterotopie versteht, als Raum neuer sozialer und politischer Formationsprozesse. Indes ist diese Vorstellung des anderen Raums womöglich allzu strikt gedacht, während Copleys Bedeutungsgenerierung und -spektrum geradezu fluid zu nennen sind. Insofern entspricht sein Konzept neuen, äber Foucault hinausgehenden Ansätzen der kulturwissenschaftlichen Meeresforschung: Vgl. Philip E. Steinberg, Of Other Seas: Metaphors 54 Horror wird hier Erschauern, Erschrecken, Schaudern und Grausen). Horrorfilm, der häufig mit der Unheimlichkeit des Bösen resp des Teufels arbeitet, ganz Copley den Hai als Inbegriff der Hölle inszeniert. Wichtig ist auch die Oszillation zwischen Lo wenden und Toten für das Horrorgenre, die Copley ebenfalls vorwegnimmt. Siehe atch Stein 1976 (wie Anm 35) S. 92, wo mehrfach die nightmare world of the foreground "in Copleys Cemälde beten wird, ohne diese Beobachtung weiter zu vertiefen.
Wucht des jungen Mannes mit der Harpune intensiviert. Nicht die Augentäuschung, sondern das Gemachtsein des Bildes als Bild, dessen künstlerische Komposition dominiert. Die Bausteine des Bildes stellen nicht die Elemente einer Erzählung dar, sondern bleiben jeweils für sich sichtbar bestehen (dies dürfte einer der wesentlichen Unterschiede zur fotografischen Adaption von Copleys Bild in den Medienbildern der Migrationskrise sein). Die formale, von messerscharfen Konturen betonte Bildsektion erfordert und erlaubt eine separierende Wahrnehmung all dessen, was Copley als gelehrte Kunstfertigkeit des akademischen Malers vorführt: die Stadtvedute, die sich über die Horizontale des oberen Bilddrittels erstreckt; die klassisch aufgebaute zentrale Gruppe, die er mit ausdrucksstarken Gesichtern und Gesten versah.

Umstandslos zeigte Copley gebildeten Betrachtern, dass er mit der Grammatik des Ausdrucks, wie sie Charles Le Brun für akademische Künstler vorgelegt hatte, vertraut war. Der Vergleich des Mannes mit der Harpune mit Le Bruns Typus der "Aufmerksamkeit" aus seiner Conférence [...] sur l'expression générale et particulière, die 1734 auch in einer englischen Ausgabe erschienen war, ${ }^{55}$ verdeutlicht dies, ebenso wie auch der Vergleich der Vorzeichnung für den links im Boot sich befindenden Jungen mit der Beschreibung des Ausdrucks einfachen körperlichen Schmerzes - alles Beobachtungen, die in der bisherigen Forschungsliteratur zum Gemälde geradezu kanonisiert sind. ${ }^{56}$

Nicht zuletzt diente Copley die Figur des weißen Jungen dazu zu zeigen, dass er den nackten menschlichen Körper auf der Grundlage anatomischen Wissens darzustellen vermochte. So verankerte er sein Werk in der seit der Renaissance obligatorischen Wissensgrundlage des Künstlers, aber auch in der zeitgenössischen Aktualität naturphilosophischer Forschung der Aufklärung. Worum könnte es Copley bei dieser Bezugnahme im Einzelnen gegangen sein? Welche Bedeutung könnte naturwissenschaftlichen Bildern und Konnotationen für Watson and the Shark beizumessen sein? Solche Fragen sind bisher nicht erwogen worden, obgleich aufschlussreiche Quellen aus den Naturwissenschaften bereits erhoben wurden. ${ }^{57}$

\section{Wissen versus Angst}

Von Copley sind bekanntlich anatomische Zeichnungen aus den 1750er-Jahren erhalten, also noch aus der Zeit, als er in Boston lebte. Die Figuren zeigen deutlich, dass er nach dem seit der Renaissance als Standardwerk geltenden Anatomieatlas von Andreas Vesalius De Humani corporis fabrica (1543) zeichnete (Taf. LXXIII). ${ }^{58}$ Viel naheliegen-

55 Charles Le Brun, A Method to Learn to Design the Passions, Proposed in a Conference on their General and Particular Expression, übers. von John Williams, London 1734.

57 Vgl. u. a. Emily Ballew Neff, Like Gudgeons to a Worm. John Singleton Copley's "Watson and the Shark and the Cultures of Natural History, in: Ballew Neff und Weber 2013 (wie Anm. 15), S. 162-

58 Andreas Vesalius, De Humani corporis fabrica Libri septem, Basel 1543. 
der wäre, dass Copley John Tinneys 1743 erschienenes Compendium Anatomicum, das in zahlreichen Auflagen bis 1842 als Handbuch für Künstler diente, konsultierte. ${ }^{59}$ Die Kupferstichtafel IV einer Écorché-Figur von Tinney nach Vesalius mag für den ambitionierten Künstler besonders inspirierend und aktuell gewesen sein (Taf. LXXIV). Besonders die Halsmuskeln, ja auch der nach hinten gelegte Kopf und die wie im Leid geöffneten Lippen mochte Copley für seine Jungenfigur übernommen haben. Tinneys Traktat dürfte auch für den Entwurf des Mannes mit der Harpune nicht unbedeutend gewesen sein. Eine männliche Écorché-Figur aus Tinneys Traktat, die einen Stock hält, wirkt wie ein Vorbild für die muskuläre Anspannung, die Copleys Figur mit den starken Waden und Oberarmen aufweist (Taf. LXXV) 60

Bisher ist in der kunsthistorischen Suche nach ikonografischen Vorbildern vor allem Copleys Rückgriff auf Alte Meister - Raffael, Tizian, Rubens und deren Nachfolger betont worden, was aufgrund der akademischen Praxis naheliegt. So wird Copley die Figur des Jungen an Raffaels (1483-1520) Transfiguration (1518-1520) angelehnt haben. ${ }^{61}$ Hier sind selbstverständlich die Themen der Erlösung und der Heilung in Anschlag gebracht worden, deren ja, im übertragenen Sinn, auch der junge Brook Watson harrt. Schließlich setzt, motivgeschichtlich gesehen, der junge weiße Bootsmann wie der Erzengel Michael in Guido Renis Gemälde von ca. 1635 dazu an, die Bestie, respektive den Satan, in die Hölle zurückzuschicken. ${ }^{62}$

Neben der Bezugnahme auf die Geschichte der bildenden Künste scheint es für Copley jedoch von ebenso großer Bedeutung gewesen zu sein, das Gemälde auf wissenschaftliche Grundlagen gestellt zu sehen, wie die lehrbuchartige Betonung der menschlichen Anatomie zeigt. Eine fast zeichnerisch zu nennende Auffassung der Malerei, die Auseinandersetzung mit planimetrischen und stereometrischen Analysen, Anatomie und Ausdruckskunde und nicht zuletzt die Kenntnis wissenschaftlicher Bilder sind für das Gemälde ebenso wichtig, wenn nicht prägender als Zitate der italienischen Hochrenaissancekunst und die Bezugnahme auf christliche Motive. Zudem ließ Copley auf seiner Grand Tour eine umfassende Neugier und Beobachtungsgabe walten, wie sie im Diskurs des 18. Jahrhunderts in England und Frankreich als Voraussetzung für wissen-

59 John Tinney, Compendium Anatomicum: Or a Compendious Treatise of Anatomy, Adapted to the Arts of Painting and Sculpture [...], London 1743 .

$60 \mathrm{Zu}$ überprüfen wäre noch der Bezug Copleys auf das Werk von John Francis Rigaud, der zwischen 1772 und 1815 seine Werke in der Royal Academy of Arts ausstellte und ebenfalls Tinneys Anleitung herangezogen haben dürfte.

62 Guido Reni, Erzengel Michael, um 1635, Öl auf Leinwand, $293 \times 202 \mathrm{~cm}$, Santa Maria della Concezione dei Cappuccini, Rom. Vol hierzu Busch 1992 (wie Anm 47) S. 40 43 . Emity Butla Concezidie wichtigsten, in men und weist dar iüber hinaus auf den Stich Jonas und derWal (De vis spuwt Jona uit op het tond) von Antonie Wierix (II) nach Maerten de Vos (siehe z. B. Rijksmuseum Amsterdam, RP-P-OB-9374) hin der fïr Copleys Gestaltung des Haiangriffs vorbildlich gewesen sein Könnte: Ballew Neff 2013 (wie Anm. 57), S. 162-195, hier S. 176f., Abb. 166 schaftliche Neuentdeckungen beschrieben wurden. ${ }^{63}$ In dieser Hinsicht war er ein experimenteller Avantgardist, der aber gerade aufgrund dieser Haltung in Kunstkreisen auch als verrückt, weibisch und kindlich abgetan wurde. Mit dieser Zuschreibung konnte sich sein Reisepartner jedoch langfristig nicht durchsetzen. Diese Gewichtung zugunsten wissenschaftlich-empirischer Grundlagen lässt sich anhand der Darstellung des Hais besonders gut verdeutlichen, der bis dahin im monumentalen Historienbild noch nie figuriert hatte.

So verwendete Copley die vergleichsweise reiche naturkundliche, illustrierte Literatur des 17. Jahrhunderts als Bildquelle. Insbesondere Agostino Scilla kommt hier infrage denn Scilla beharrte darauf, seine wissenschaftlichen Zeichnungen, die als Stiche 1670 zuerst erschienen (Abb. 1), als Künstler angefertigt zu haben. Er schloss damit an Leonardos Argumentation der Malerei und Zeichenkunst als wissenschaftliche Medien an 1696 legte William Wotton der Royal Society einen Abriss von Scillas Werk vor und veröffentlichte ein Jahr später $A$ Vindication of an Abstract of an Italian Book concerning Marine Bodies. ${ }^{64}$ Scillas Werk war ein Gegenentwurf zur bibeltreuen Naturauffassung von Athanasius Kirchers Mundus subterraneus von $1664 .{ }^{65}$ Es zeigte Vergleichbarkeiten, aber eben auch Diskrepanzen zwischen der Naturstudie und den Fossilien bzw. Versteinerungen und Abdrücken als Spuren vormaligen Lebens auf, was der Vorstellung eines unveränderlichen, universellen Naturplans göttlicher Ordnung widersprach und die Natur als veränderliche, prozesshafte Geschichte begreifbar machte. Unabhängig von Scilla hatte der dänische Anatom Niels Stensen unter der Patronage der Medici drei Jahre zuvor seine Zeichnungen einer Sektion eines für wissenschaftliche Studien gefangenen Hais publiziert, eine Abhandlung, die von Robert Hooke (1635-1703) nich unbeeinflusst gewesen sein soll und in englischer Übersetzung dem Umkreis englischer Empiristen und Künstler zugänglich war (Abb. 2). ${ }^{6}$

63 Siehe dazu Anita Hosseini, Die Experimentalkultur in einer Seifenblase. Das epistemische Potenzia in Chardins Malerei, Leiden/Boston 2017, Kap. 1.2.5., "Aufmerksamkeit und Neugier. Die Spiel der Kinder und die Experimente der Wissenschaftler, S. 92-100 zum Diskurs uber den wissenschaftlichen Erkenntrisprozess sowie die grundsät liche Bedeutung von empirischer Beobachtung und Neugierde als Ausloser fur Netentdeckungen. Die Autorin versucht, dasen nataxphilosophischen Diskurs, den maßgeblich. Lorraine Daston untersucht hat, mit Chardins Darstellungen des Wissensen piels in Verting der Ensü̈r ang wissenschaft und Kunst, wie sie Michael Baxandall für Chardin und Werner Busch fïr zahlreiche englische Künstler enent Derart direkte Aneignungen Busch fur zlunger

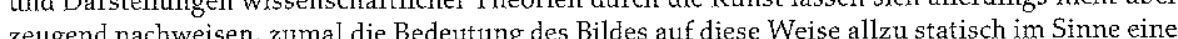
Abbildens von Theorie verstanden wird, anstatt die mediale Aktivität, Prozesshaftigkeit, diskursive Produktivität und Erkenntnisweise der Künste in Anschlag zu bringen.

64 Siehe Paolo Rossi, The Dark Abyss of Time. The History of the Earth \&' The History of Nations from Hooke to Vico (itaI Originalfassung 1979), aus dem Italienischen übers. von Lydia G. Cochrane, Chicago/London 1984, S. 24.

65 Athanasius Kircher, Mundus subterraneus, Amsterdam 1664.

66 Nicolaus Steno, Elementorum Mrologiae Specimen, seu Musculi descriptio Geometrica. Cui accedun canis carcharine dissectum caput, et dissectus piscis ex canum genere, Florenz 1667. Vgl. zu Stensen 


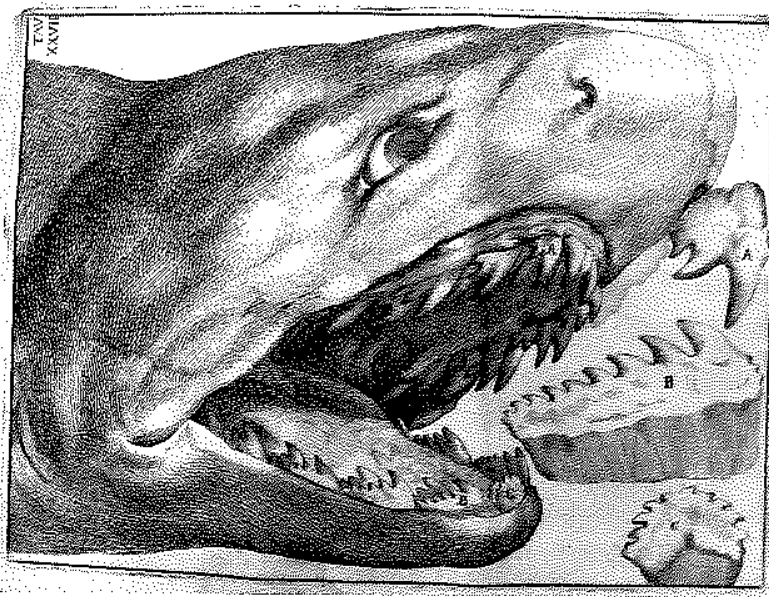

1 Agostino Scilla, La vana speculazione disingannata senso. Lettera risponsiva circa corpi marini che petrificatisi trovano in varij luoghi terrestri, Neapel 1670, Tafel XXVII

Auffallend ist, dass Copley in der Kopfhaltung des Hais und in der Art des aufgerissenen Mauls die Ikonografie dieser wissenschaftlichen Darstellungen übernimmt. Es lag ihm indes fern, eine dieser naturwissenschaftlichen Illustrationen direkt in sein Werk zu implementieren oder deren Ästhetik gänzlich zu übernehmen. Eben das erklärt die von Zeitgenossen und Kunsthistorikern beklagten Fehler der Darstellung des Hais: Copley mischt die damals bekannten, allerdings raren Bilder von Haien, malte wohl nach Haigebissen in anatomischen Sammlungen und fügte seinem Amalgam die üblichen Elemente von Walen und Seemonstern hinzu - besonders die, Lippen' des Haies wirken übertrieben und von der Form her allzu zugespitzt, sodass sich ein wundersamer, aber doch Objektivität beanspruchender Hybride ergab. ${ }^{67}$ Diese Mixtur würde Copleys

Beiträgen zur Geologie und Fossilienkunde Dominik Collet, Die Welt in der Stunde. Begegnungen mit Außereuropa in Kunstkammern der Frunen Neuzeit, Gottingen 2007, S. 181. Siehe zur Erforschung von Haien in der Frahen Neuzert Jane P. Davidson, Early Modem Supematural. The Dark Side of European Culture, 1400-1700, Santa Barbara/Denver/Oxford 2012, hier den Abschnitt "Shark Teeth, S, 3 Perbet gie in 17. Jaht. New York 2011, S. 809-858, rew Verghen Vergehen begriffenen Erde insgesamt am Herkömmlichen rüttelt; in der Tat rückt er , in gefährliche Vol. Emily Ballew Nefs Dis....

(1) (wie Anm. 57), S. 181-186. Die Autorin kommt zu folgenden Schlussfolzu diskutieren: In fact, Copley's painting is the first to move away die damalige Naturphilosophie logy and toward a shark more in concert with the booming interest in natul history in mythotenment culture of the time. [ ] The broad ronge of exang the interest and advancement of zoology and ethnography at the time. Watson and the Shasgoth

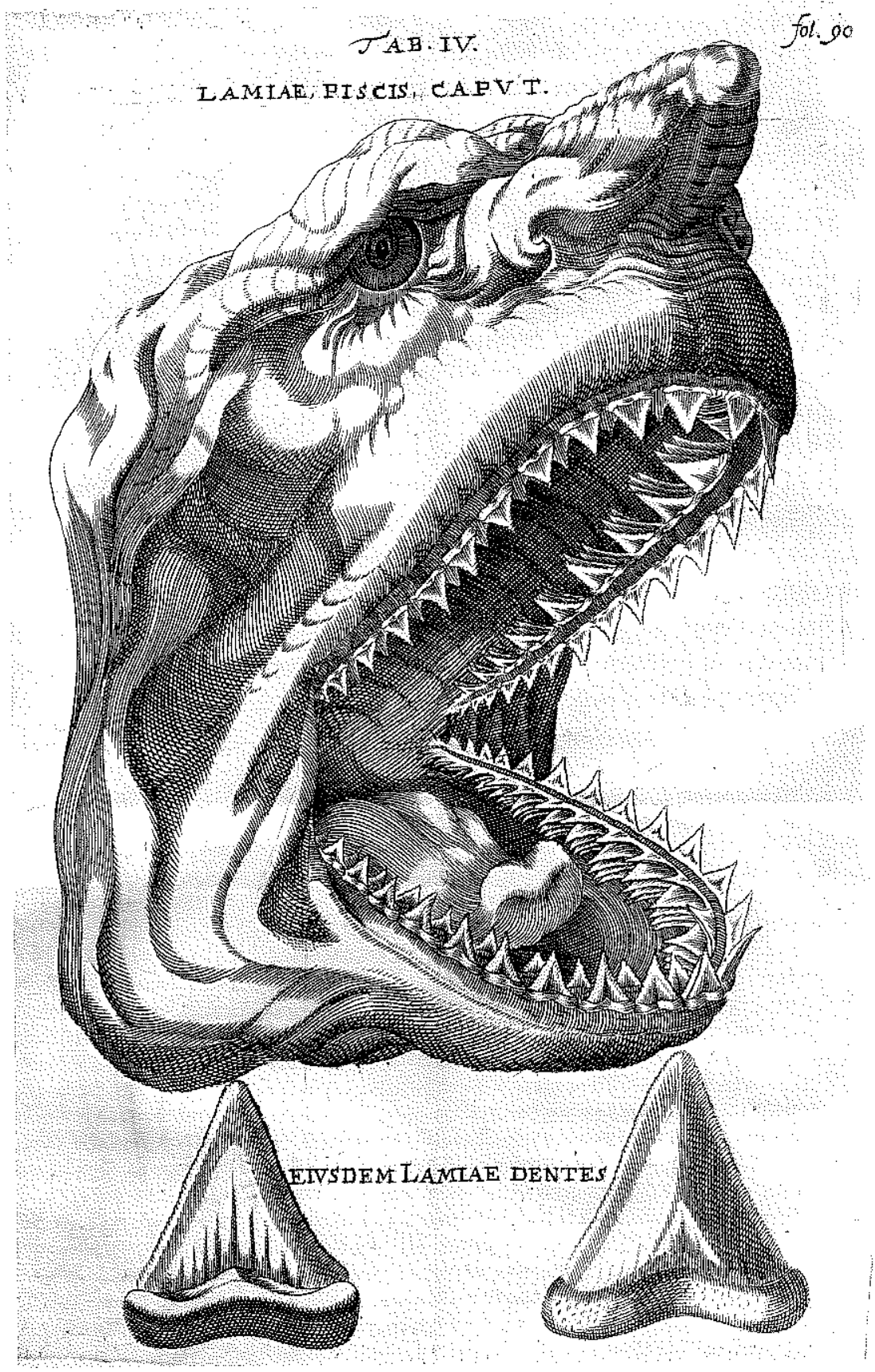

2 Niels Stensen, Lamiae piscis caput, aus: Elementorum myologiae specimen: seu Muscul descriptio Geometrica. Cui accedunt Canis Carchariae dissectum Caput, et dissectus piscis ex canum genere, Amsterdam 1669, S. 140, Tafel IV 
Strategie entsprechen, das Neue - die Haidarstellung - mit Bildelementen und Allusionen der Tradition zu verblenden. Alles andere wäre zu radikal und unverständlich für Zeitgenossen gewesen. Diese Beobachtung unterstützt, dass Copley an einer neuen Bild findung arbeitete, die sicher auch die Durchschlagkraft des medial weit zu verbreitenden Stichs implizierte. Mit anderen Worten:

Bekanntlich muss sich alles - hand̆le es sich um Dinge oder Personen - in seinen Anfängen zwangsläufig verstecken. Wie sollte es anders sein? Tauchen sie doch plötzlich in ein Anfangen menhang auf, der sie noch nicht enthielt, und müssen sie doch zunëchst die Gemein Zusambetonen, die sie mit der Gesamtheit teilen, um nicht auf Ablehnung zu stoß3en." ${ }^{\circ 68}$

Indem Copley die sichelartige Rückenflosse darstellt und im rechten Mittelgrund die Schwanzflosse platziert und so proportional die Riesenhaftigkeit des Fisches betont, lässt er gleichwohl keinen Zweifel daran, dass er sich mit dem großen Weißen Hai beschäftigt haben muss. Der lateinische Name des Riesenfisches, Canis Carcharias, stammt aus dem 16. Jahrhunder ${ }^{69}$ und überdeckt gleichsam die mythologische Dimension des für Kinder und Jugendliche albtraumhaft beängstigenden, haiartigen und vampiristischen Seemonsters Lamia, eine Bezeichnung, die für den Weißen Hai in Italien in der Frühen Neuzeit gängig war und nicht zuletzt mit der tatsächlichen Präsenz des Monsterfisches in den mediterranen Gewässern einherging. ${ }^{70}$ Das aufgerissene Maul und die erhobene Schwanzflosse gehören zum Drohgebaren des Raubtiers, dessen Darstellung Copley zur Angsteinflößung nutzt. Zweifellos ging es Copley um eine moderne, empirisch bestimmte und zugleich archetypische Formgestaltung der Angst. ${ }^{71}$

tapped into and helped shape the popular understanding of these subjects. Copley was not a natura historian, nor was his painting practice completely transformed by the growing culture of natura history as a discipline, although surely he was aware of its enhanced role and the importance of research as he moved forward with other successful contemporary history paintings." Ebd., S. 1.83, 68 Deleuze 1997 (wie Anm. 3), S. 15

99 Canis Carcharias wurde als wissenschaftliche Bezeichnung der Spezies bereits 1553 von Pierre Belon in seinem Werk De aquatitibus, Libri duo [...] (Paris 1553) verwendet (S. 60)

70 Heute lautet die lateinische Bezeichnung Carcharodon carcharias. Lamia war der griechischen Mythologie zufolge eine in ein Monster verwandelte, ehemäls libysche Königin, die mit Zeus Kinder hatte. Hera, Zeus' Frau, trieb ihre Rivalin in den Wahnsinn, indem sie ihr die Kinder nahm. Ihr Sohn Acheilus war besonders schön und erregte die Eifersucht von Aphrodite, die ihn in einen kleinen Hai verwandelte. Lamia wird auch als Geist oder Vampir beschrieben. Die nach ihr benannten Lamien, blutrünstige Monster, die es besonders auf Kinder und Jugendliche abgesehen hatten, waren der Kunst und Literatur des 18. Jahrhunderts bekannt. Siehe u. a. Robert E. Bell, Women of Classical Mythology: A Biographical Dictionary, Santa Barbara 1991, S. 271-271; Jonathan B. Durrant und Michael D. Bailey (Hg.), Historical Dictionary of Witchcraft, 2. Auflage, Lanham/
Toronto/Plymouth 2012, S. 119

Toro 1 M.

Mit der his heute unternehmerisch gearbeitet, wie das letztlich gescheiterte Projekt "Shark City" zeigt, das 2017 zu Kontroversen führte und 2018 umpublic.de/kein-hai-gefaengnis-in-sinsheim/ (Terthter Zug animal public e. V.: http://www.animalder der Sozialbiologie, Edward O Wilson (geb, 1929) has die Faszination von Menschen für Haie und andere Raubtiere damit zu begrïnden versucht, dass durch immer wieder neu herg ture zählungen eine Haltung gegen̈̈ber diesen hedrohlichen Wesen entïnde die letzlich - atelte Er schiere Panik - dem Überleben dient. Wilson ist heftig für seine Zü̈dführung mo -
Wir haben es also mit einem Gemälde zu tun, das auf eine Vielzahl von Quellen zurückgreift und in der Hochkunst ebenso verankert ist wie in der wissenschaftlichen, empiristischen Illustration. Schon allein dieser Befund zeigt, wie wenig eindeutig Copley sein Werk angelegt hat. Und es besteht neben der Öffnung von Eindeutigkeit auch kein Zweifel, dass Copley sich derart als hochgebildet, virtuos und autonom hinsichtlich akademischer Regeln darstellte. Seine großen Publikumserfolge gaben ihm recht - er hatte eine Art Sensationsbild konzipiert, welches das anonyme Publikum ansprach und in seiner Quellenlage so komplex war, dass Kunstkritiker und Theoretiker ihm den Respekt nicht verweigern konnten. Der Hai, der noch Züge frühneuzeitlicher Monstren aufweist, erzeugt als künstlerisch-wissenschaftliches Mischwesen die Präsenz eines Ungeheuers, das auch staatstheoretische Inhalte aufruft. Repräsentiert es die vielfache Gefahr des bösen Staatskörpers, vor der sich die junge Gesellschaft Amerika an der Schwelle zur Staatengründung ebenso in Acht nehmen muss wie vor dem englischen Mutterland? In jedem Fall forciert das Wesen die Angst, die der Mensch zivilisatorisch zu bekämpfen, aber auch um der Gemeinschaft willen einzusetzen hat, um seine Triebhaftigkeit zu unterdrücken. Einmal mehr versteht es Copley, altes und neties Wissen, alte und neue Bilder zu verschmelzen, ohne selbst politisch Position zu beziehen. Und nur so kann er das exfüllen, was ihm so oft in der Forschungsliteratur zugeschrieben wurde, nämlich ein Bild für die Zukunft erschaffen zu haben. ${ }^{72}$

ethischer Überlegungen und Verhalten auf naturgegebene Bedingungen kritisiert worden. Allerdings kann man nicht von der Hand weisen, dass Bilder - sei es in der Malerei oder im Film ebenso wie in der Literatur - kontinuierlich derartige Erzählungen konstruieren. Wilson gilt als Kritiker des von Herbert Spencer und Charles Darwin geprägten und popularisierten Theorems, The Survival of the Fittest'.

72 Der Hai wăre mithin der Leviathan, bevor Hobbes aus dem "animalischen Monstrum der Bibel" eine ${ }_{\text {"Menschengestalt" }}$ werden lässt: „Er ist Ungeheuer allein in seiner Riesengestalt: seine Formen sind die der Menschen, die ihn geschaffen haben." Horst Bredekamp, Behemoth als Partner und Feind des Leviathan. Zur politischen Ikonologie eines Monstrums, in: Leviathan 37 (2009), Nr. 3, S. 429-475, hier S. 455-456. Allerdings bleibt der Hai ein Mischwesen, das den irrationalen und den rational objektivierten Körper vorführt. Copleys Hai trägt das biblische Monstrum und das rationale Kalkü in sich. Zuerst hat Roger B. Stein darauf hingewiesen, dass Copleys politische Haltung "seem to have been intentionally obscure" Stein 1976 (wie Anm. 35), S. 89; siehe zum Ausgreifen Copleys au die Zukunft ebd. S. 97. In der großen Biografie, die Jane Kamensky Copley gewidmet hat und für die sie erstmals umfassend auch die Briefe der Familie ausgewertet hat, folgt sie dieser Sicht, wenn sie gleich eingangs feststellt, dass der Maler, wie Nelson Goodman formuliert hätte, konfligierende Wahrheiten der "revolutionary world" darstellte und es bevorzugte, sich auf keine politische Seite zu schlagen: Kamensky 2016 (wie Anm. 27), S. 3. Die emotionale Bravour, mit der diese umfassende Biografie als Spiegel der Revolutionszeit geschreben ist, zeigt die Ber hinows diend in den Ver-

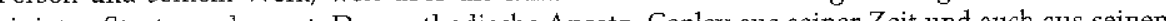
einigten Staaten zukommt. Der methodsche Ansatz, Copley aus sein self-made"; ebd S. 8) zeig die eher einsitio Aurrichtung der kunsthistorischen Forschung darauf, Künstler und Kunstwerk in den Mirtlpolt zu stellen, a in den M.telpunk zu in ihrer. Uhse. thodisch und theoretisch problematisch. Es handelt sich um sich ergänzende Wissensbereiche, die 


\section{Wahrnehmung als Differenzerfahrung}

Welche Rolle hat die Figur des das Seil haltenden Mannes in Watson and the Shark, und inwiefern ist die oben angedeutete ethische Entscheidungssituation, die in der Bildwahrnehmung über die Lesbarkeit hinaus evoziert wird, von Relevanz?

Copley hat für diesen Protagonisten eine heute im Detroit Institute of Art befindliche Kopfstudie angelegt, ohne jedoch den mimischen Ausdruck mit den direkt den Betrachter anblickenden Augen und dem wie zum Sprechen geöffneten Mund unmittelbar in sein Gemälde zu übernehmen (Taf. LXXVI). Beide Gesichter verbindeł aber eine gewisse mimische Indifferenz.

Es ist auffallend, dass die Figur in Watson and the Shark, im Unterschied zu den anderen Protagonisten des Bildes, eine verhaltene, nach Le Bruns Ausdrucksgrammatik nicht ohne Weiteres zu dechiffrierende Mimik zeigt. Irritiert äußerten sich darüber bereits Copleys Zeitgenossen, die in Zeitungskritiken den Ausdruck als wie gefroren im Schreckenszustand verstehen wollten. Der Kunsthistoriker Albert Boime betonte wiederum die auffallende Eleganz der Figur. ${ }^{73}$ Damit wollte er hervorheben, wie ungewöhnlich die ganzfigurige Darstellung eines Schwarzen als Akteur ikonografisch für die Zeit des 17. und 18. Jahrhunderts war. So hatte etwa Benjamin West im. Gemälde Tod des General Wolfe einen Vertreter der indigenen Bevölkerung Nordamerikas trauernd an die Seite des Hauptprotagonisten gestellt. Sowohl die native americans wie die afroamerikanische Bevölkerung hatten seit dem 17. Jahrhundert in verehrender oder dienender Haltung weißen Protagonisten in Historienbildern, in monumentalen Jagdszenen wie in Porträts gegenüber oder besser zur Seite zu treten

Copley dagegen setzt den schwarzen Mann erhoben und in direkten formalen und inhaltlichen Bezug zu dem weißen Jungen, dessen Hand der des Ersteren korrespondiert. Beide blicken sich direkt in die Augen. Keiner der anderen Protagonisten hat diese formale und inhaltliche Beziehung zum weißen Jungen, auch nicht der auf Kopfhöhe mi dem Seiltragenden zum Stoß ansetzende weiße Mann, der sich auf die Tötung des Hais konzentriert.

Der Protagonist mit dem Seil ist direkt in die Entscheidungssituation des Bildes involviert und übernimmt damit eine zentrale Rolle im dramatischen Geschehen. Er ist derjenige, der dem Jungen im Wasser unmittelbar helfen kann.

Unter ihm, sogar zwischen diesen beiden Hauptfiguren des Bildes, hat Copley den älteren Mann direkt in die Blicklinie der zwei Hauptprotagonisten gemalt. Im ersten Entwurf zum Gemälde sollte hier ein jüngerer Mann dargestellt werden. Auch die stehende Figur des Mannes mit dem Seil trägt andere Züge, wie eine Vorzeichnung für die zentrale Figurengruppe zeigt (Taf. LXXVII). Copley hat erst im Zuge des Werkprozesse neben der Überarbeitung verschiedener Gesichtsausdrücke und Physiognomien auch

73 Albert Boime, Blacks in Shark-Invested Waters. Visual Encodings of Racism in Copley and Homer in: Smithsonian Studies in American Art 3 (1989), Nr. 1, S. 19-47, hier S. 22.

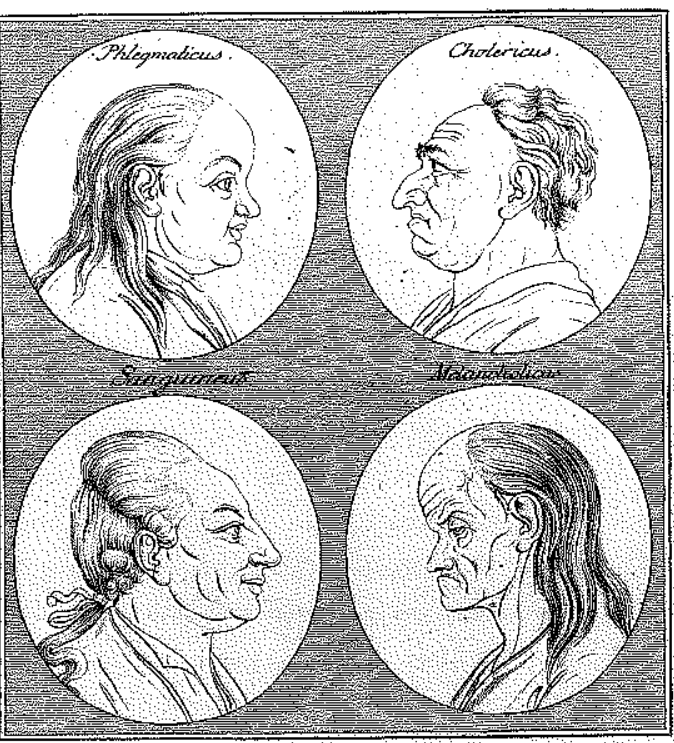

3 Johann Caspar Lavater,

Phlegmaticus, aus: Physiognomische Eragmente, zur Beförderun von Menschenkenntniss und Menschenliebe, Vierter Versuch, Erben, 1778, Tafelband, S. 53

weitere Aspekte wie Schwarz versus Weiß, Alt versus Jung in die Komposition integriert und damiz die Dramatik unmissverständlich gesteigert. Der Alte zeigt einen Ausdruck ängstlicher, erstaunter Furcht, vermutlich kombiniert mit der Physiognomie des Phlegmatikers, wie in einer Profildarstellung aus Lavaters Physiognomischen Fragmenten (1775-1778) zu sehen, die zu der Zeit, als Copley sein Bild malte, in London kursierten (Abb. 3). Ängstlichkeit und Selbstbezogenheit als Gefühlslage des Phlegmatikers solche Dispositionen hatte bereits Aristoteles als Inbegriff einer unethischen Haltung ansehen wollen. Insofern ist auch zu fragen: Befindet sich der Alte auf dem Rückzug, und will er einen der weiß gekleideten Jungen ins Boot zurückziehen - oder hält er ihn nur sichernd fest? Wie auch immer entschieden wird, hier deutet sich eine der Ambivalenzen des Bildes an. Und dann der Junge links am Ruder, der den Ausdruck körperlichen Schmerzes zeig $\mathrm{t}$ - nimmt er den Ausgang des dramatischen Angriffs durch den. Hai vorweg? Der im Wasser treibende nackte Junge, dem der Hai den rechten Unterschenkel verletzt oder schon abgerissen hat - das Wasser erscheint hier blutig gefärbt -, wird so gesehen zum Opfer werden. An dieser Stelle in der Bildkomposition hängt gleichsam alles an einem seidenen Faden, an eben dem Seil, das der Junge zu fassen sucht und das ihm der Mann auf dem Boot gerade ausgeworfen hat.

Die aufklärerische Thematik der Erziehung des Menschen ist in das derart dramatisch wirkende Bildgefüge offenkundig eingewoben. Denn so wie der alte Mann gan im Sinne von David Humes These, der Mensch agiere grundsätzlich aus seinem Selbst- 
interesse heraus, dieses nun in Anschlag bringt und, anstatt sich selbst weiter der herein brechenden Cefahr auszusetzen, die junge Mannsch bleibt der das Seil tragende Protagonist die einzige Person, derzun festgeleot erscheint. In ihrer aber unmitebar bevor datiter damit die des Betrachters spiegeln, nämlich die, trotz der schrecklichen Gefahr, entschlossen die Rettung zu vollziehen.

Hier ist die Kategorie der sympathy angesprochen, die des Mitgefühls, des Mitleids, in dem sich das Selbstinteresse zugunsten der Anteilnahme am Schicksal des anderen im Sinne einer Kultivierung der eigenen Gefühle verringert. Für David Hume war diese Kategorie ebenso wie für Adam Smith besonders zentral, denn nur in der sympathy könne sich der Mensch als Mensch ausbilden. ${ }^{74}$

Smith war daran gelegen, dass der Mensch diesseits einer bildungs- und wissensbegründeten Urteilsfähigkeit eine aus seiner Sicht natürliche Eigenschaft entwickele, damit der allgemeine Naturprozess der menschlichen Gesellschaft sich zum Guten wende. Da wird von Smith, dem Autor von The Wealth of Nations, der in der Unabhängigkeitserklärung Amerikas das bedeutendste Ereignis der Weltgeschichte schlechthin sehen wollte, nicht als interesseloser Akt verstanden, sondern als Grundlage für eine Gesellschaft, die durch einen im Individuum entwickelten Gemeinsinn wirtschaftlich lukrativ und zivilisatorisch fortschrittlich sich weiterentwickeln und dem Glück entgegenstreben könne. Copleys mehrheitlich jugendliche Gemeinschaft steht an der Schwelle, sich des auf sympathy gegründeten Zusammenwirkens, des Miteinanders zu besinnen und nicht nachzugeben. Der Protagonist mit der Harpune und der Mann mit dem Seil sind die Entscheidungsträger und Handelnden, denen die anderen im Boot und mit diesen auch Entscheidungsträger und $\mathrm{H}$
der Betrachter folgen sollen.

Wird im Weiteren der historische Kontext des Somerset-Falls berücksichtigt, in dem Lord Mansfield letztlich entschied, dass in England kein Gesetz zur Versklavung von Menschen herrschen und daher auch ein entkommener Stlavetz zur Versklavung Obhut seines ,Besitzers' gezwungen werden könne, so wird vorstellbar, welches Statement Copley dem eleganten Mann mit dem Seil aIs Held für sein damaliges Publikum mitgegeben haben könnte. Der Ort Havanna als Teil der Westindischen Inseln, welche ein Territorium des Sklavenhandels waren, der schwarze Seemann als ein Typus und Akteur, der die Sklaverei konterkarierte und zumindest auf dem Meer bestimmte festAefügte gefügte Rollen und Besitzansprüche infrage stellte, und nicht zuletzt die Eleganz und die Schönheit, die damals so populäre Figuren wie der freie und wohlhabende Afrikaner William Ansah Sessarakoo (aktiv 1736-1749) ausstrahlten, Autor von The Royal African: or, Memoirs of the Young Prince of Annamaboe (1750), ${ }^{75}$ - alle diese Elemente der

74 Siehe Hartmut Reck, Die Ethik des englischen Sensibilitätskultes in ihren literarischen und malerischen Manifestationen (Europaische Hochschulschriften, Reihe XXVIII Kunstgeschichte 395), Frankfurt am Main/Berlin/Bonn 2003, S. 28-35, Abschnitt 2.2.2., "Sympathie als Gesellschaftsprinzip bei
David Hume".

75 Siehe Ballew Neff 2013b (wie Anm. 57), S. 171.
Debatten und der Erfahrungen der damaligen Zeit werden von Copley zwar assoziativ aufgerufen, aber als Künstler bezieht ex sich nicht eindeutig und ausdrücklich auf spezifische Quellen, und er nimmt auch nicht deutlich Partei im zeitgenössischen Diskurs. Es bleibt dem Betrachter überlassen, die Synthese des Dargebotenen formal und inhaltlich trotz der bis zu einem bestimmten Grad fragmentierten Bildelemente zu vollziehen. Unter dieser Voraussetzung hat Copley bei aller Gelehrsamkeit und Wissenschaftlichkeit seines Bildes eine mitreißende und tiefgründige Szene entworfen, die an die Frage des Menschseins schlechthin rührt. Auf diese Weise konnte sein Bild als Kunstwerk und als ethisches Lehrstück für das anonyme Publikum und also auch für diejenigen, die die dargestellte Geschichte nicht kannten, erfolgreich sein.

Personen, die Copleys Werk aus einer inneren Distanz heraus lesen, werden sich dessen humanitärer Aussage nicht versichern können. Denn Copleys Kunst mit dem Hai beinhaltet die Umkehrung jener konservativen Rigidität, mit der Reynolds , the vulgar', den Pöbel, aus den Ausstellungen und von der Kunstrezeption ausgeschlossen sehen wollte. Aus dessen Sicht sollte sich das, learned eye, das gebildete Auge, an Gemälden voller Wissen über die Kunst erfreuen. ${ }^{76}$ Vor Copleys Bildern sollte der Betrachter jedoch darüber hinaus seiner eigenen Sinnestätigkeit gewahr werden und sich humanisieren. Aufklärung steht hier im Zeichen eines Wahrnehmungsprozesses. Die Auseinandersetzung zwischen den weißen und dem schwarzen Protagonisten des Bildes wird zur Differenzerfahrung des Bildbetrachters. Erst so wird das durch das Bild erzeugt, was es darstellt. Nicht die Trennung, sondern die Präsenz des Nichtmenschlichen und Animalischen, die Präsenz der Differenz lässt die Fragen nach und die Antworten auf Menschlichkeit und Menschenrechte lebendig bleiben. Mit Copley steht ein Künstler vor Augen, der diese Präsenz wachhält. Copley stellte sein Werk in einer Zeit aus, in der auf der Grundlage von John Lockes (1632-1704) politischer Philosophie die Menschenrechte erklärt wurden. Er scheint in seiner Kunst eine Philosophie der Menschenrechte ausgelegt zu haben, die die gesamte Moderne, ihre menschlichen Triumphe, Katastrophen und Auslassungen umfasst, wie es einzelne zeitgenössische Texte und Diskurse nicht vermochten. Für diesen essenziellen Schritt brauchte es letztlich keine akademische Bildung - darin bestand Copleys rebellisches Statement, und dies wird einer der Gründe dafür sein, weshalb das Gemälde bis heute seine aktive Wirkung entfaltet.

Mit seiner Signatur auf der Innenseite des Bootes gesellte sich Copley gleichsam zu der Gemeinschaft, in die sich als humane Gesellschaft auch der Bildbetrachter fügen sollte. Wie sinnfällig die Tatsache war, dass ausgerechnet ein Künstler aus den amerikanischen Kolonien die Selbstentdeckung des eigenen Menschseins offerierte, lässt sich in den Worten John Lockes ermessen: Anfangs sei die ganze Welt ein Amerika gewe-

76 Gockel 1999 (wie Anm. 7), Kap. II. „Bedeutungsstiftung durch Wahrnehmung: Akademische und antiakademische Kunst im Widerstreit", besonders S. 78-82 und S. 90f. 
sen. ${ }^{77}$ Die ethische Grundhaltung, die er in seinen zwischen 1680 und 1682 verfassten und 1689 anonym erschienenen Zwei Abhandlungen über die Regierung der zivilen und politischen Gemeinschaft ins Stammbuch schrieb, setzte das Erfahrungswissen ihrer selbst voraus. Auf der Tabula rasa des Selbst müsste dieser Mensch erst im Dialog von "sensation" und "reflection" seine ethische Grundhaltung ausbilden. Diese Theorie, die in die Unabhängigkeitserklärung einfloss, bildet Copley nicht ab. Vielmehr bietet er seine Kunst als Erfahrungsmedium an, durch das der erschauernde Betrachter sich als Mensch erst zu entdecken (und zu entscheiden) hat, aufgrund einer Differenzerfahrung, die Denken und Handeln überraschend neu in Gang setzt. ${ }^{78}$

\section{Fiktion und Funktion}

1783 vollendete Copley im Auftrag von James Boydell ein Bild, das den Überfall französischer Truppen auf der britischen Kanalinsel Jersey zum Thema hat, und stellte es im Mai 1784 täglich von 20 Uhr bis Mitternacht im Great Room am Haymarket Nr. 28 aus, nachdem es zuerst dem König und der königlichen Familie vorgeführt worden war und deren höchste Lobpreisungen erhalten hatte (Taf. LXXVIII). ${ }^{79}$ In dem tumultarti-

77 Wörtlich heißt es bei Locke (Kap. 5, „Das Eigentum", Paragraf 49): "So war anfangs, und zwar weitaus mehr, als es heute der Fall ist, die ganze Welt ein Amerika, denn so etwas wie Geld war überall
unbekannt." Walter Euchner (Hg.), John Locke. Zwei Abhandlungen über die Regierung Frankfurt am Main 1977, S. 230. In Kap. 4 Von der Sklaverei" wendet sich Locke deutlich regen die Stlaverei, was einer der Gründe für die Anonymisierung seiner Schrift gewesen sein dürfte, da er damit quer zur noch lange vorherrschenden naturrechtilichen und auch wirtschaftlichen Begründun von Sklavenhandel und Sklavenhaltung lag. Siehe zur problematischen Naturalisierung Amerikas durch Locke, der die Besiedlung aus einer Kombination von Naturrecht und Nutzen rechtfertige: Lazaros Milopoulos, Attantische Zivilisation und transatlantisches Verhältnis. Politische Idee und Wirklichkeit, Wiesbaden 2007, S. 205-207.

78 Insofern ist es verkiurzt, Copleys Gemälde mit der Ästhetik des Erhabenen zu erklären.

99 Siehe die Ausführungen zu diesem Bild auf der Website der Tate Britain: http://www.tate org ak/art/artworks/copley-the-death-of-major-peirson-6-january-1781-n00733 (letzter Zugriff am 9. Juli 2017). Statt die montageartige, den narrativen Verlauf gerade nicht eindeutig darstellende Komposition zu betonen, wird das Gemälde durchaus subtil in eine eindeutig erzählerische Beschreibung der historischen Ereignisse eingebunden. Siehe zusammenfassend zur Auftragslage Louise Downie und Doug Ford, 1781: The Battle of Jersey and The Death of Major Peirson, Jersey 2012, S. 42f. Siehe zur Ausstellungssittlation und zu den zeitgenossischen Ausstellungsbesprechungen in allen namhaften Zeitungen Londons Prown 1966 (wie Anm. 37), S. 306f. Der König soll auch gerade Boydells Engagement fur Kunst als offentliches Medium gelobt haben. Die Beschreibung des schwarzen Protagonisten in The Death of Major Peirson und die Narrative, die dem Gemalde - ebenso wie Watson and the Shark-im musealen Kontext zugeschrieben werden, zeigen, dass nicht allein im Nachhinein ein gesichertes Geschichtsbild quasi belegt wird, sondern dass in unterschiedichen Zusammenhangen ganz unterschiediche Lesarten entstehen, die mit der kulturpolitischen oder sogar politischen Agenda von Institutionen und Personen zu tun haben. Insofern st ein Gemalde ganz konkret und aktiv in die Steuerung von Haltungen, Meinungen, Emotionen nind Geschichtsauffassungen eingebunden. Die Anthropologin Rosa De Jorio fasste die Forschung aber Erinnertng, Geschichtskonstruktion und Identitat wie folgt zusammen: "The process of reDe Jorio Narrations of

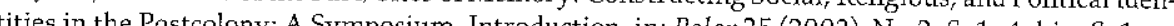

Geschehen lassen sich Bruchstücke verschiedener Phasen des historisch verbürgten gen Gesche ausmachen. Für unseren Zusammenhang ist wichtig, dass Copley eine verdichtete, in dieser Weise historisch so nicht gesicherte Szene entwirft, in der der junge, tote Major Francis Peirson (1757-1781) von seinen Kameraden in der Formel der Grablegung Christi gehalten wird. ${ }^{80}$

Sein Haar hat sich gelöst, wie das Haar des Jungen in Watson and the Shark. Ein neuer Zustand jenseits der gesellschaftlichen Rolle wird markiert, die sonst nur noch dem Jungen zugeschrieben wird, der zu der fliehenden Gruppe aus zwei Frauen und einem Säugling am rechten Bildrand gehört. ${ }^{81}$

Der tote, jugendliche Major, fast selbst noch ein halbes Kind, wenn man so will, wird n eine Sphäre gerückt, die nicht mehr eindeutig männlich konnotiert ist - ein Aspekt, der mit damaligen politischen Debatten über männliches Heldentum weiter zu unter suchen wäre ${ }^{82}$ Copley löst damit die Polarität von Männlich/Weiblich zugunsten eine Mischform auf, was gut zu seiner auf Komplexität ausgerichteten Konzeption passt. ${ }^{83}$

80 Siehe zur Ikonografie der Gruppe Prown 1966 (wie Anm. 37), S. 305f. Copleys Figuren und Figurengruppen in Death of Major Peirson zeigen ihn einmal melr als Kunstler, der das akademische Repertoire der Bezugnahme auf klassische Vorbilder von der Antike über die Renaissance bis zul Kunst des 17. Jahrhunderts aufzurufen, zu synthetisieren und zu transformieren wusste. Die mittlere Gruppe lässt an die Ikonografie der Beweinung Christi denken, wie sie in Sandro Botticellis Werk vor Augen steht, das sich heute in der Alten Pinakothek, München, befindet und im 18. Jahr hundert in den Uffizien verwahrt wurde. Siehe Sandro Botticelli, Beweinung Christi, Pappelholz, um $1495,140 \times 207 \mathrm{~cm}$, Bayerische Staatsgemäldesammlungen, Alte Pinakothek, München. Botticellis Gemälde mit religiösen Themen teilen mit Copleys Historiengemälden den Verzicht auf Tiefenräumlichkeit zugunsten der Monumentalisierung der Figuren und Szenen. Es scheint nur ein Zufal zu sein, dass Botticelli sein Bild als Reflex auf eine Zeit der Machtumwälzungen, des Kriegs und der Weltuntergangsstimmung im damaligen Florenz malte und die radikalen Predigten Girolamo Savonarolas mit der französischen Invasion Italiens zusammenfielen; Botticelli mithin wie Copley bildlich auf eine nationale Krisenzeit reagierte. Schrecken und Leid, wie sie sich in der Mimik un Körpersprache in Copleys Gemalde ausdrücken, erinnern an die Niobiden-Gruppe, die 1769/70 nach Florenz gebracht wurde und 1638 von François Perrier als Stich veröffentlicht worden war. Auf Poussin, von dessen Gestaltung variantenreichen Ausdrucksvermögens sich Copley währen seines Parisaufenthalts angetan zeigte, hatten die Statuen nachweislich großen Einfluss.

81 Zieht man Hoocks Ansicht heran, der meint, in Copleys Death of Major Peirson zeige sich in de Gruppe der Frauen mit den Kindern ein Statement gegen den Krieg, dann deutet sich die Moglichkeit an, in Copleys Bildkonzept nicht nur die affektive Note zu sehen, sondern auch den deutenden, kommentierenden, Meinung machenden Aspekt. Siehe Hoock 2010 ( S. 95.

82 Copleys wie auch Wests Gemälde werden in der Forschungsliteratur auch als "death-of-the-hero pictures" bezeichnet: Siehe Leo Costello, Turner, West, and the End of Contemporary History Painting, in: Ballew Neff und Weber 2013 (we Ann

83 Vgl. Joseph Wright of Derby, The Dead Soldier, R.A. 1789, Ol auf Leinwand, $126,4 \times 162,6 \mathrm{~cm}$, The University of Michigan Museums of Art and Archeology, 2006/1.156. Nachstich von James Fieath The Dead Soldier, Mai 1797, ausgestellt in, "New Ro 21 Gemälde und 11 Druckgrafiken zu sehen George Washington seine Bildergalerie zeigte, waren. Der tote Soldat des gelösten Haars eine gewisse Ahn hert. Krieg fordert. Deshalb scheint George Washington die Druckgraik di ihm als Geschenk reschickt wurde, in den repräsentativen Raum seines Landsitzes aufgenommen zu haben. 
Die offenen Haare des Majors signalisieren die buchstäbliche Auflösung seiner Rolle, indizieren aber auch in der Art der möglichen Feminisierung des Helden eine Korrespondenz mit dem Federbusch des Schwarzen. Denn Federn als Haarschmuck galten im 18. Jahrhundert als übertriebene Details der Frauenmode. Der aufgetürmte Kopfschmuck mag Zeitgenossen auch an die Macaroni erinnert haben, die mitunter in Karikaturen auch mit militärischen Details ausstaffiert wurden. Copley, der selber gern in zeitgenössischer Mode schwelgte, wird Details solcher Art benutzt haben, um sein Gemälde als ein zeitgenössisches Werk auszuweisen. Ob es sich um eine intendierte Feminisierung des Majors handelt, muss offen bleiben. Allerdings feminisiert der Reisegefährte Copleys 1774 den Künstler explizit, indem er ihn als weibisch und viel zu gesprächig beschrieb. ${ }^{84}$ Derartige Feminisierungen gehörten zu den Codes einer sich verändernden Politik der Geschlechterrollen. Es wäre falsch den Einsatz dieser Codes im Einzelfall überzuinterpretieren. Vielmehr nutzte Copley ästhetisch deren performativen Zwischenraum und inhaltlich die Anmutung von Fluidität vormaliger Rollenkonzepte und Bedeutungszuweisungen.

In den Vorzeichnungen und Skizzen für das Bild wird der Soldat, der den Major rächte, indem er den Schützen der tödlichen Schüsse selbst tödlich traf, zunächst nich explizit als schwarz entworfen (Taf. LXXIX). ${ }^{85}$ Erst relativ spät - auch dies vergleichbar mit Watson and the Shark - muss sich Copley für einen schwarzen Helden entschieden haben. Unbeirrt, mit zielgerichteter Durchstreckung des gesamten Körpers legt er an und zielt. Copley eröffnet mit dieser Figur die Thematik des schwarzen Soldaten spezifisch der an der Seite der Briten kämpfenden befreiten Sklaven, die während der amerikanischen Revolution nach Nova Scotia, auf die Westindischen Inseln und nach London verbracht wurden. Die Geschichte der ,Black Loyalists' wie überhaupt die Rolle der afroamerikanischen Soldaten im Unabhängigkeitskrieg ist noch wenig erforscht, nicht zuletzt weil die individuellen Geschichten und Identitäten kaum überliefert sind. ${ }^{86}$ Copley könnte die Geschichte der Kompagnie Bucks of America gekannt haben, einer Einheit, in der freie Schwarze und Sklaven dienten und die später, um 1789, von John

84 Siehe zu Copleys Grand Tour Ballew Neff 2013a (wie Anm. 14), v. a. S. 121-126. George Carter, Copleys Reisegefährte, schrieb über den Künstler: „I cannot help and take him for a Woman with Child, for he longs and wishes for every Thing [sicl he sees, and always fancies every Thing [sic] is better than that which he possesses." Zit. nach ebd., S. 125.

85 Vgl. die Farbabbildungen in Ballew Neff 1995 (wie Anm. 15), Kat.-Nr. 19 bis Kat.-Nr. 32
86 Fest

zurückzuerstatten. Fine zentrale Quell gewillt war, nach dem Krieg den Amerikanern ihr, Eigentum zurückzuerstatten. Eine zentrale Quelle für den Vorgang ist das Book of Negroes, das in drei Versionen in England, Kanada und den Vereinigten Staaten aufbewahrt wird. Interessant ist, dass - im Protagonist in Copleys The Copley - auf einer Website über das Book of Negroes der zentrale wird: http. Im Unterschied mentar, dem zufolge der Schwarze ein Diener gewesen in der Regel dem zeitgenössischen Komdenbildung beruhen dürfte, unterstreicht Klinke 2011 (wie. Dass dies ungeklärt ist und auf Legengeht nicht auf die spezielle Kloidur dem Gemälde The Death of Major Peirson ebd, S. 83-90.
Hancock und seinem Sohn mit einer Flagge und einer Plakette geehrt wurde. ${ }^{87}$ George Washington konnte sich erst zu einer vollständigen Unterstützung schwarzer Rekruten bekennen, nachdem die Briten ihrerseits deren Kampfbereitschaft und Freiheitsstreben für ihre Seite zu nutzen wussten. Durch diese Auseinandersetzungen und Initiativen war die Figur des schwarzen Soldaten auf beiden Seiten des Atlantiks eine vielfache Meinungen auf sich ziehende Neuerung. ${ }^{88}$ Auch von dieser Neuartigkeit profitierte Copleys Gemälde als Ausstellungsbild in einer öffentlichen Sphäre.

Mit dem Federbusch und der eleganten Kleidung ist diese Figur eine mit dem Seiltragenden in Watson and the Shark vergleichbare Erscheinung. Die physiognomische Schönheit wird offenbar auch als moralische Schönheit eingesetzt. Rettung, Rache und Verteidigung werden mit dem schönen Schwarzen, mit dem, was viel später in der Bürgerrechtsbewegung des 20. Jahrhunderts als ,Black Beauty' tituliert werden sollte, verbunden. Auch wenn der eigentliche Nationalheld Major Peirson ist, so ist doch die über die Diagonale angelegte Komposition darauf ausgerichtet, dass der Betrachter diese Figur entdeckt und über ihre Rolle nachzudenken beginnt.

Entsprechend rankten sich schnell Anekdoten um diesen Soldaten, der angeblich, obgleich das in keiner Weise gesichert ist, ein Diener des Majors gewesen sein soll, wie schon in der Broschüre zur Ausstellung des Gemäldes festgehalten wurde. ${ }^{89}$ Man gewinnt den Eindruck, dass von Anfang an die Diskurse, die sich um das Gemälde rankten, dessen spektakuläres und ikonisches Potenzial herunterzudimmen hatten. Diese Legendenbildung war wohl dafür gedacht, die Rolle dieser Schlüsselfigur festzuschreiben und sie als treuen Diener zu sehen, obgleich dies der von Copley erfundenen Figur in ihrer bildlichen Präsenz nicht gerecht wird, ja dem heldenhaften Auftritt sogar widerspricht. ${ }^{90}$ Eine andere Legende will, dass Copley den Diener des Auktionators James Christie zum Vorbild genommen haben soll. In einer der Vorstudien zur zentralen Gruppe, in der über den Köpfen der Figuren deren Namen festgehalten wird, steht ausgerechnet über der rächenden Figur, die noch gar keine Darstellung eines Schwarzen zu erkennen gibt und

87 Siehe Margot Minardi, Making Slavery History: Abolitionism and the Politics of Memory in Massachusetts, Oxford/New York 2013, S. 163.

88 Siehe zur ausführlichen und differenzierten Darlegung der Beteiligung Schwarzer am Amerikanschen Unabhängigkeitskrieg: Karsten Fitz, The American Revolution Remembered, 1830s to $1850 \mathrm{~s}$. Competing Images and Conflicting Narratives (= American Studies. A Monograph Series 186) Heidelberg 2010, S. 166-219. Ich stimme mit Fitz überein, dass Albert Boimes Analyse, Bilder als Texte zu lesen und sie als Aquivalente eines rassistischen Diskurses zu verstehen, eindimensiona ist. Siehe ebd., S. 169. Auf Copleys Darstellung von Schwarzen trifft Boimes Schlussfolgerung schon deshalb nicht $\mathbf{z u}$, weil der Kunstler bewusst vielstimmig aufgeladene Werke schuf, die umso mehr in die Dynamik des politischen Geschehens eingebunden waren, also in der Meinungsbildung und Erinnerungspolitik eine aktive Rolle spielten.

89 Siehe Prown 1966 (wie Anm. 37), S. 303

90 Wie problematisch die Zuschreibung als Diener ist, zeigt der Fall von Primus Hall (1756-1842), dem ein amerikanisches Gericht seine Pension, die ihm als Soldat im Unabhängigkeitskrieg zustand, mit dem Hinweis verweigerte, er habe am Krieg nur als Diener teilgenommen. In der Berufung und durch Zeugenaussagen seiner Kameraden konnte er schließlich seine Rechte durchsetzen. Zu Primus Hall siehe Minardi 2013 (wie Anm. 87), S. 63ff. 
auch keinen Federbusch trägt: "Captn Christie's Black Servt". ${ }^{11}$ Damit rückt die fiktive Gestalt gänzlich in die Sphäre der Kunst, denn Christie stellte Copley Ausstellungsräume zur Verfügung und unterstützte jene zeitgenössischen Künstler, die sich nicht immer reibungslos mit der Royal Academy of Arts ins Benehmen setzen wollten, vor allem, wenn es um die prominente Ausstellung ihrer Werke ging. ${ }^{92}$ Fast hat man den Eindruck, dass Copley geradezu im letzten Augenblick diese Aufsehen erregende Gestalt seinem Bild einfügte und diese dann legendenhaft authentifizieren wollte.

\section{Strategien der Ikonizität}

Der Künstler, dem ein „amerikanisches Herz“ zugeschrieben wurde, offerierte Historiengemälde, die gezielt viele Fragen offenlassen, die historisch Gesichertes mit Fiktion verknüpfen, die christliche Ikonografie mit profanen ikonografischen Formeln mischen un anstatt der Einheit der Erzählung deren Vielheit und Offenheit darbieten. Es schein so, dass diese Hybridität, die auch darin liegt, dass Copley Gattungen wie Gruppenporträt und Historienmalerei mischt, von der Komplexität und Diskursivität damalige Debatten in der politischen Philosophie, in Auseinandersetzungen über den Abolitionismus, Rollenbilder der Gesellschaft und vieles mehr mit erzeugt wurde, so wie Copleys Gemälde aktiv in diesen diskursiven Feldern wirkten.

Jedenfalls scheint nach 1800 und im Verlauf des 19. Jahrhunderts diese dramatische, vielstimmige Erzählweise und die dem Betrachter offerierte Geschichte mit offenem Ausgang ein Nachleben gehabt zu haben. Man denke an Géricaults Das Floß der Medusa (Taf. LXXX) oder an die Life Line (Taf. LXXXI) von Winslow Homer, die in der Forschung schon oft mit Copleys Gemälden assoziiert wurden.

Während Géricault die Grande Nation an eine beschämende Episode erinnerte, die 1816 dazu geführt hatte, dass nach dem Schiffbruch der Fregatte mit dem Namen Medusa Hunderte von Menschen dem Kannibalismus anheimfielen, tungsboote das Seil gekappt hatten, konzentriert sich Winslow Homer auf die Essenz einer dramatischen Rettungspartie, deren Ausgang trotz des Einsatzes eines technisch neuen Rettungsseils völlig offen ist. Gerade Homers Bild scheint eine Fortführung des auf den ersten Blick künstlerisch so anders, mit viel Personal und Aktion konzipierten Historienbildes Copleys zu sein: Die Rettungsleine konfrontiert den Betrachter; wir werden übergangslos in das Geschehen gezwungen, das, wie Jules D. Prown ausgeführt

91 John Singleton Copley, Study for the central group of ,The Death of Major Peirson', 1782-1783,

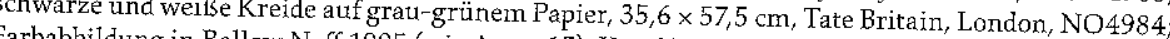

Zu Copley als Aulew Neff 1995 (wie Anm. 15), Kat.-Nr. 21, S. 144.

Karriere im modernen Kunstskunstler siehe Oskar Batschmann, Ausstellungskünstler. Kult und tal der Kunst: Gainsborousts Kunst und Karriere. Ein KG loid hat, unmittelbar Empathie und die Ingredienzien eines humanistischen Akts evoziert. ${ }^{93}$ Letztlich geht es in Homers Kunst um dieselben Fragestellungen, die Copley künstlerisch aufwarf: Wie lässt sich im Angesicht (durchaus auch vom Menschen) entfesselter Naturgewalt ein zivilisierter Zustand (wieder) herstellen? In Homers Kunst sind es die Kinder und Heranwachsenden, die den Balanceakt zwischen der Natur und ihrer Bewältigung spielerisch erlangen, während Erwachsene ihn sich mühsam erarbeiten müssen, dabei aber auch die Freuden des Zusammenhalts - buchstäblich in der ,Life Line' - wie eine erotische Begegnung erleben dürfen. ${ }^{94}$

Auch in Homers Kunst, so kann man schlussfolgern, bleibt das Konzept der Aufforderung zur Interaktion und Partizipation erhalten, solange der Künstler sich mit einem jugendlichen Optimismus und der moralischen Aufforderung zur Rückbesinnung auf entschlossenes, selbstloses Handeln in der Gemeinschaft identifizieren konnte. Für dieses durchaus pathetische Konzept eines heute vielfach kritisierten Gutmenschentum hatte Copley in den 1770er- und 1780er-Jahren die Grundlagen zugunsten eines vielstimmigen Geschichtsbildes im Sinne Barack Obamas entworfen, mit vergleichbarer ideologischer Ambivalenz, die Winslow Homer in The Gulf Stream radikal über Bord werfen sollte. ${ }^{95}$ Die Hoffnungslosigkeit und Radikalität der späten Werke Winslow Homers waren keine gute Ausgangslange für die Erschaffung von Gedächtnisikonen. Dies sollte dem geschäftstüchtig spekulativen, selbstbewussten und seismografisch die Stimmen seiner Zeit aufzeichnenden Copley vorbehalten bleiben.

93 Jules D. Prown, Winslow Homer in His Art, in: Marianne Doezema und Elizabeth Milroy ( $\mathrm{Hg}$.) Reading American Art, New Haven/London 1998, S. 264-279, hier S. 274

94. Ebd., S. 276-78, hat einleuchtend darauf hingewiesen, dass der in der Life Line mitschwingende Optimismus, der auch Homers Bildern wie Snap the Whip (1872) und Breezing Up (A Fair Wind) Optimismus, der auch Homers Bildern wie Snap the Whip (1872) und Breezing Up (A Fair Wind)
(1876) inhärent ist - beides Gemälde, die mit Copleys Werken genauer verglichen werden müssten -, in späteren Werken wie The Gulf Stream (1899) fehlt. The Gulf Stream, ein Gemälde, das oft mit Copleys Watson and the Shark in Verbindung gebracht wurde, zeigt einen schwarzen Mann auf einem unkontrollierbar gewordenen Boot, bedroht von Haien. Die Darstellung enthält Prown zufolge auch deshalb keinerlei Botschaft der Hoffnung und Ästhetik der Interaktion, weil der Mann jeden Blickkontakt mit dem Mutterschiff verloren hat.

95 Winslow Homer, The Gulf Stream, 1899, Öl auf Leinwand, $71,4 \times 124,8 \mathrm{~cm}$, Metropolitan Museum, New York, vgl. die Abb. unter: http://www.metmuseum.org/art/collection/search/11122 (letzter Zugriff am 13. September 2017). 

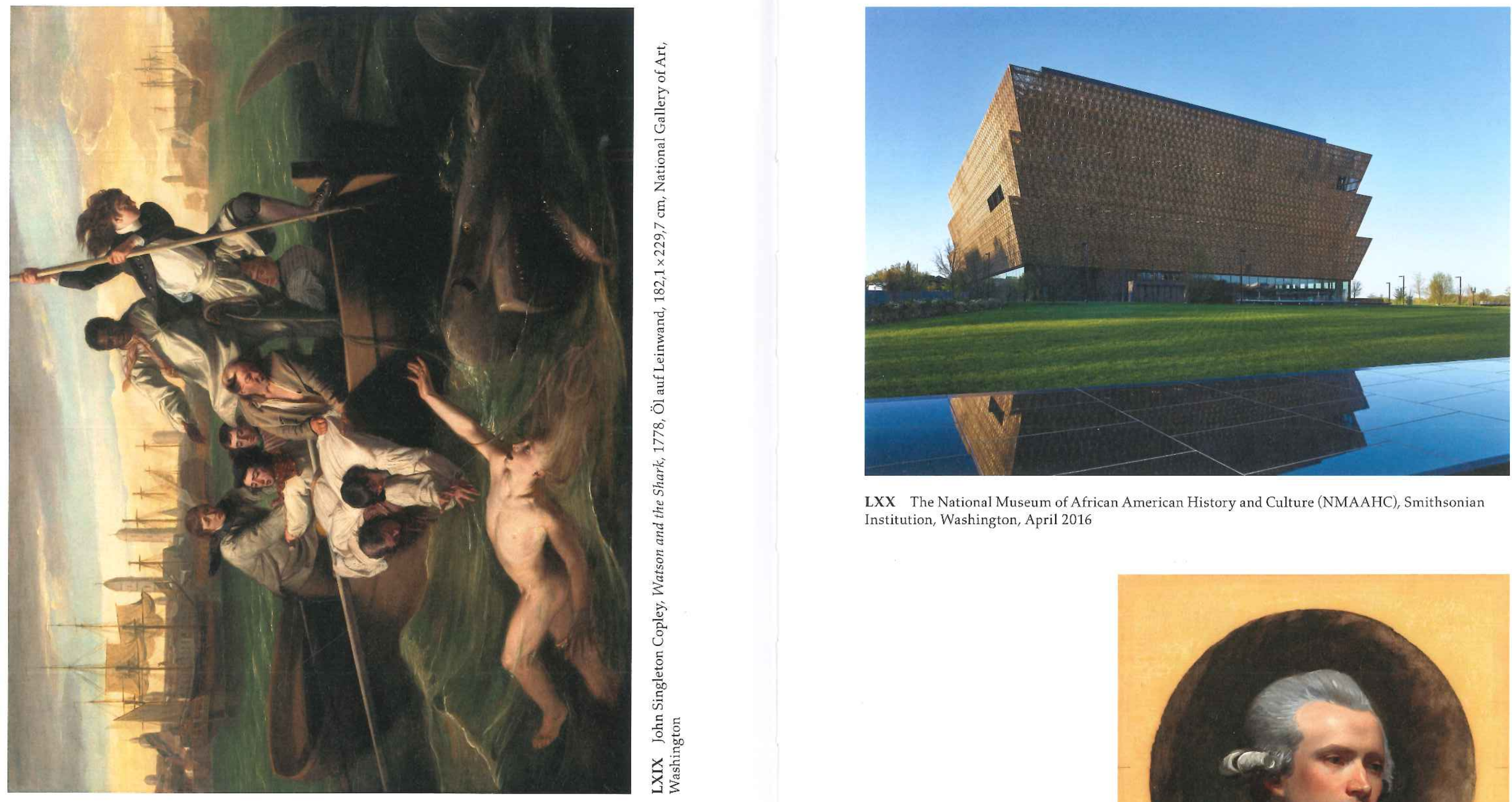

LXX The National Museum of African American History and Culture (NMAAHC), Smithsonian Institution, Washington, April 2016

LXXI John Singleton Copley,

Selbstporträt, 1780-1784, Öl auf

Leinwand, $81,3 \times 81,3 \mathrm{~cm}$, Nation

Institution, Washington

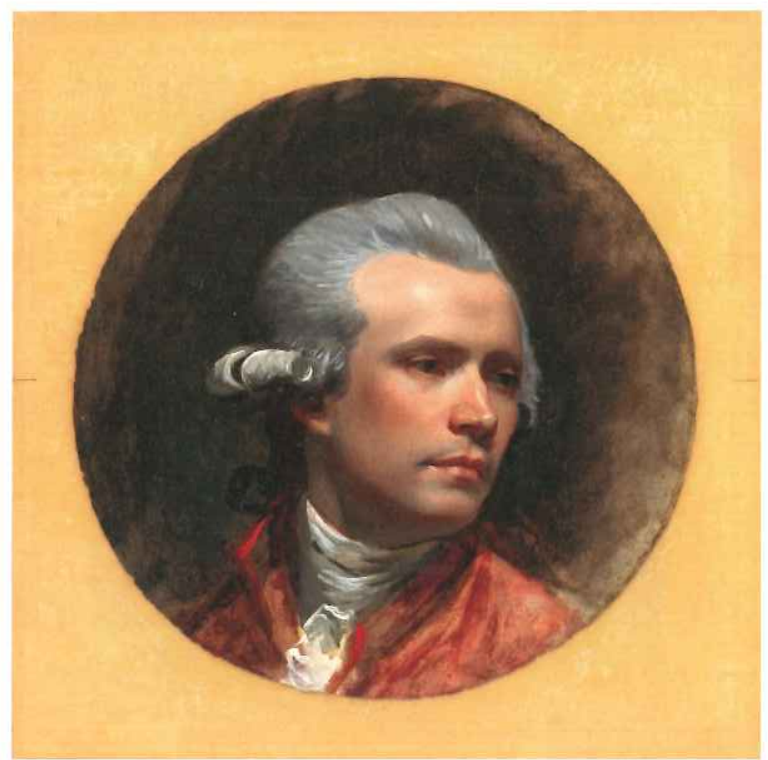




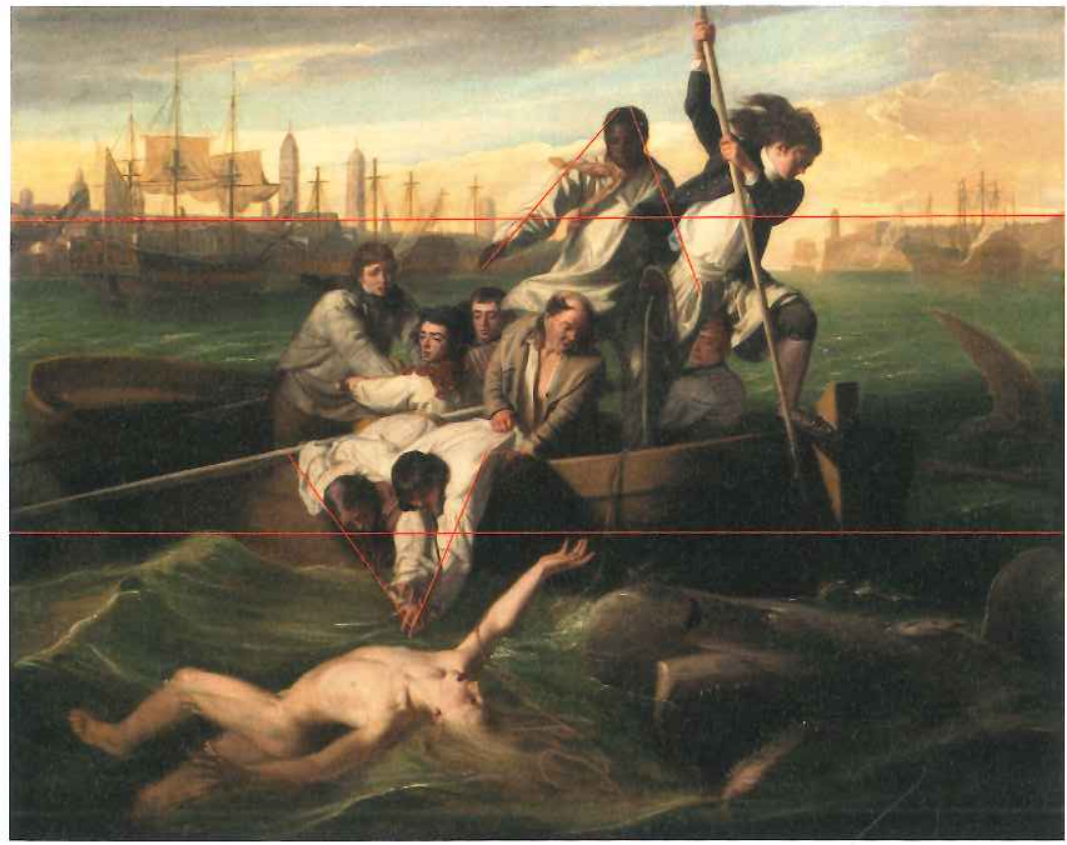

LXXII John Singleton Copley, Watson and the Shark, 1778, Öl auf Leinwand $182,1 \times 229,7 \mathrm{~cm}$, National Gallery of Art, Washington (die eingezeichneten Hilfslinien verdeutlichen den kompositionellen Bildaufbau)

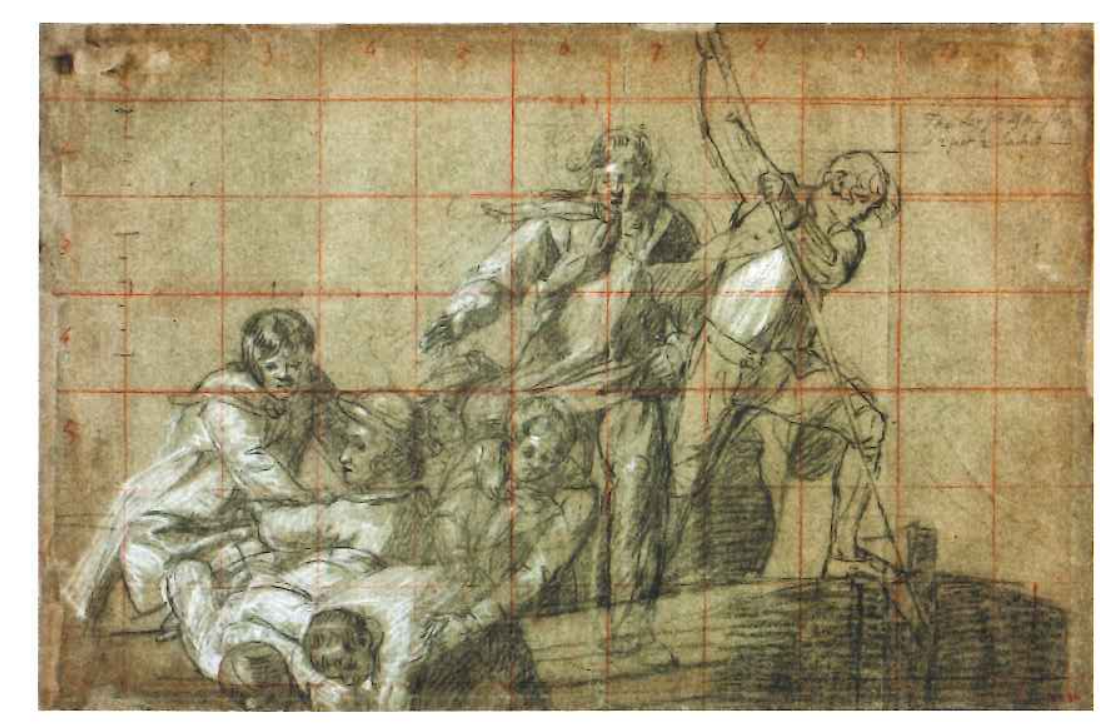

LXXVII John Singleton Copley, Rescue Group, 1777-1778, schwarze Kreide erhöht mit Weiß, mit roter Kreide quadriert, auf grün-grauem Büttenpapier, $36,2 \times 55,2 \mathrm{~cm}$,

Detroit Institute of Arts

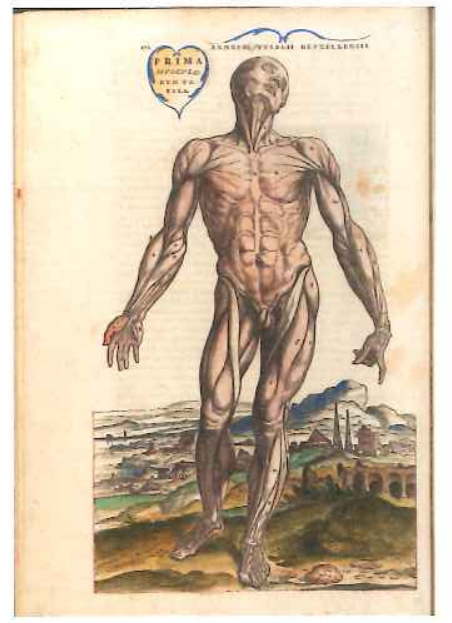

LXXIII Andreas Vesalius, De Humani corporis fab septem, Basel 1543, S. 170

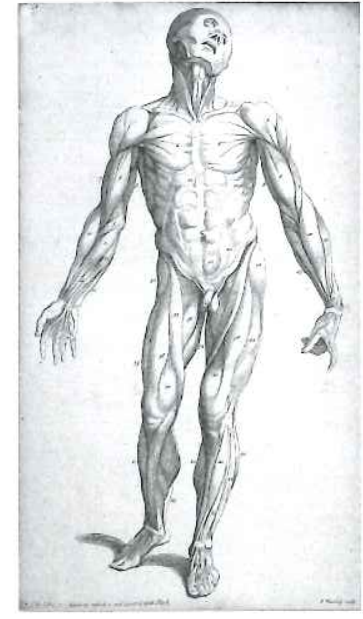

LXXIV John Tinney, Male écorché, Kupferstich in: John Tinney, Compendium Anatomicum: Or a Compendious Treatise of Anatomy, Adapted to the Arts of Painting and Sculpture [...], London 1743

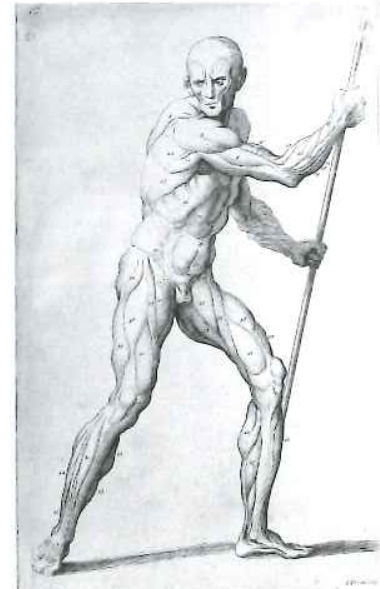

LXXV John Tinney,

Male écorché holding a staff. Kupferstich, in: John Tinney, Compendium Anatomicum: Or a Compendious Treatise of Anatomy, Adapted to the Arts of Painting and Sculpture [...], London 1743, Pl. VII
LXXVI John Singleton Copley, Head of a Negro, 1777-1778, Ol auf Leinwand, $53,3 \times 41,3 \mathrm{~cm}$, Detroit Institute of Arts

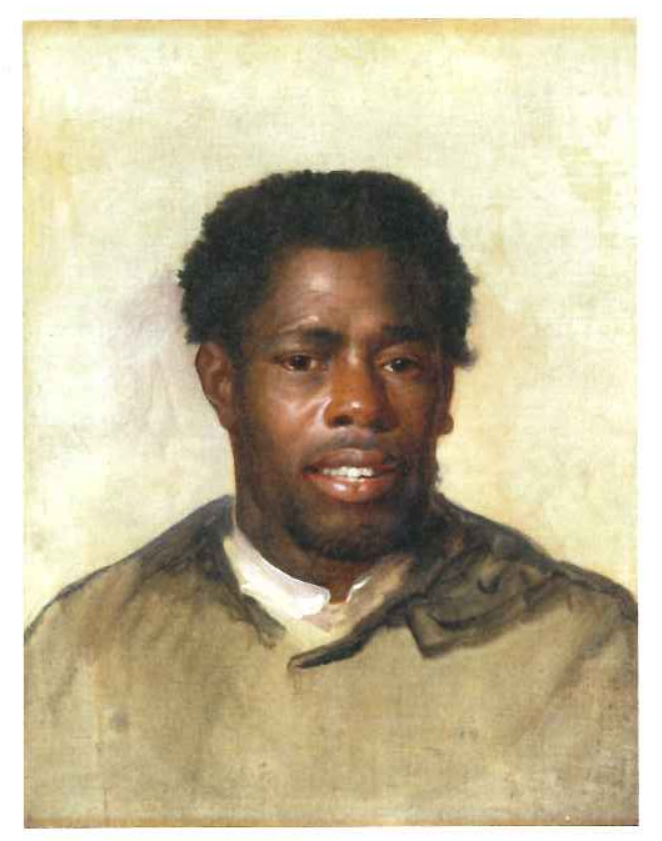



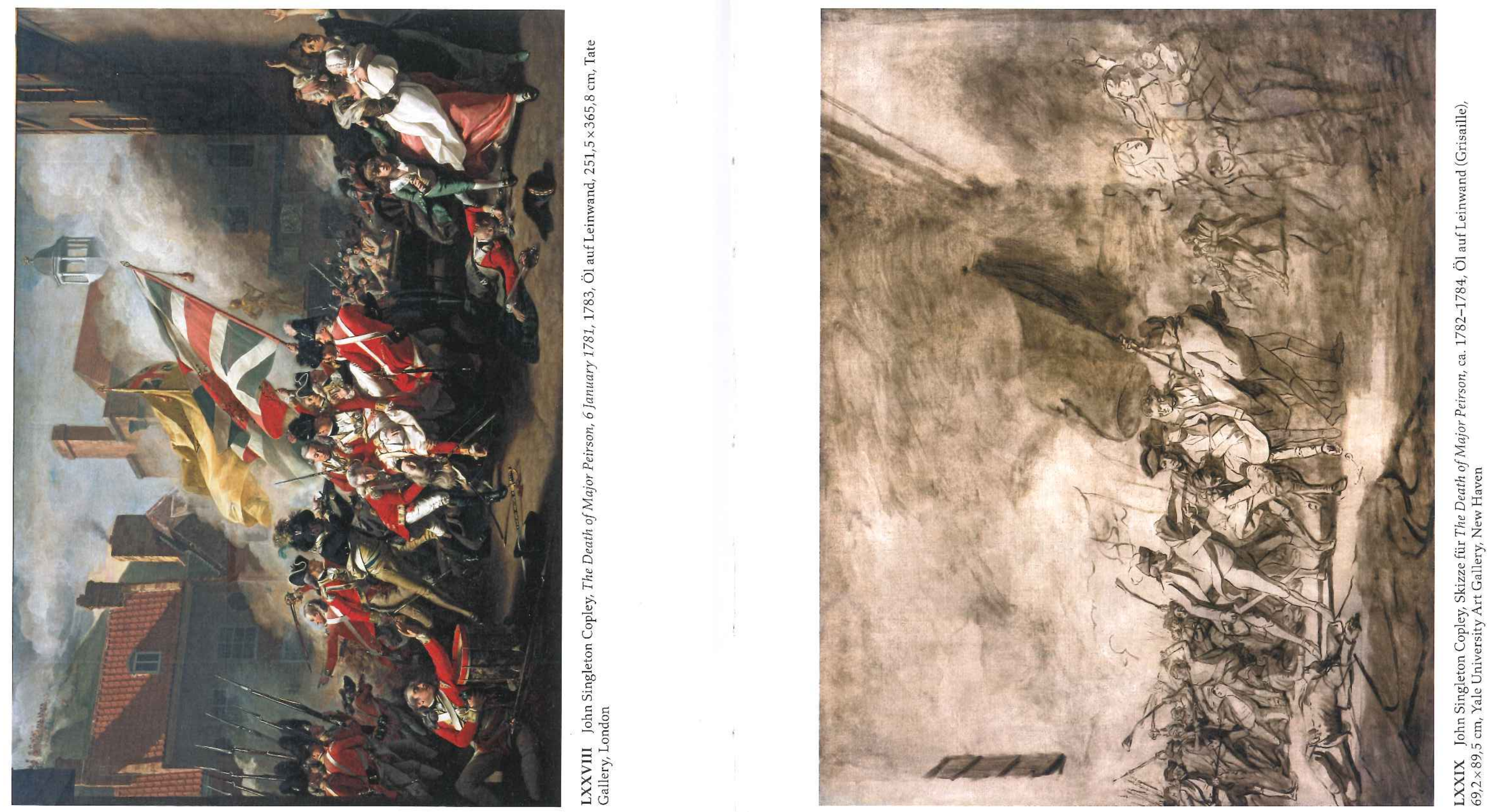


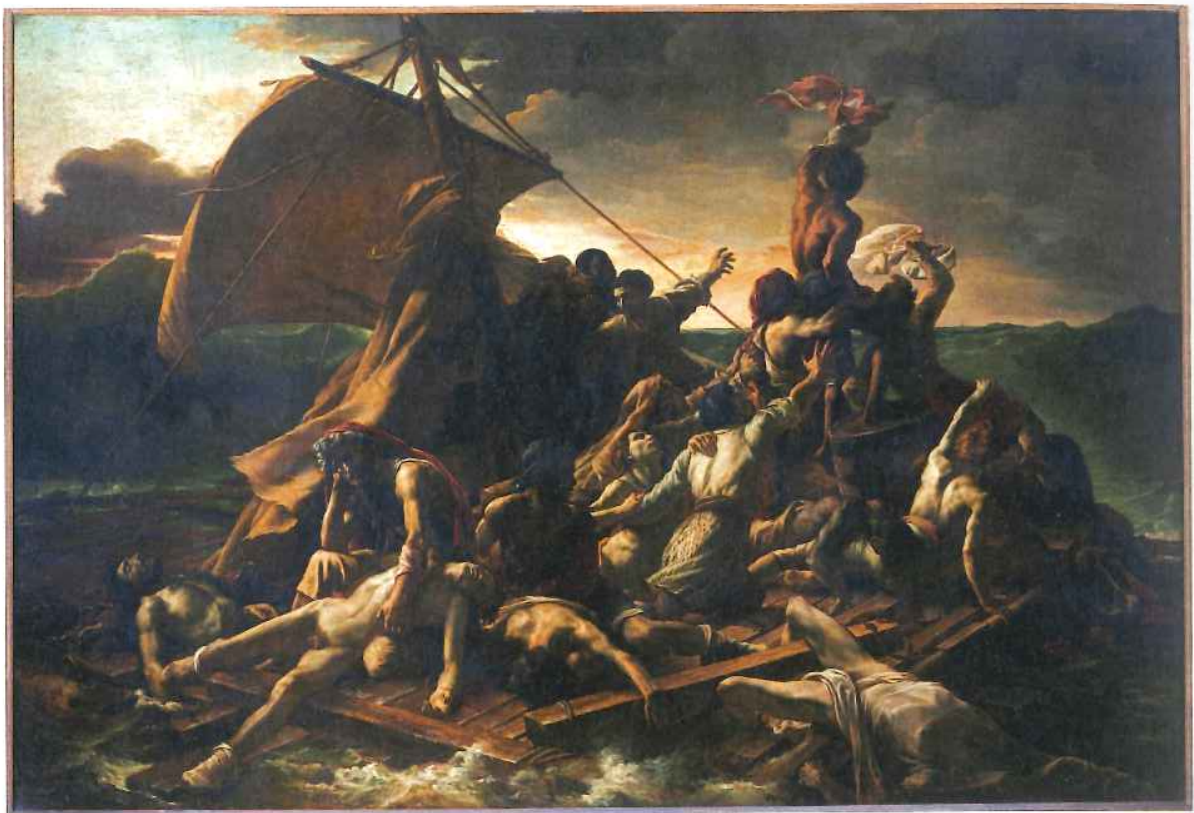

LXXX Théodore Géricault, Das Floß der Medusa, 1819, Öl auf Leinwand, $491 \times 716 \mathrm{~cm}$, Musée du Louvre, Paris

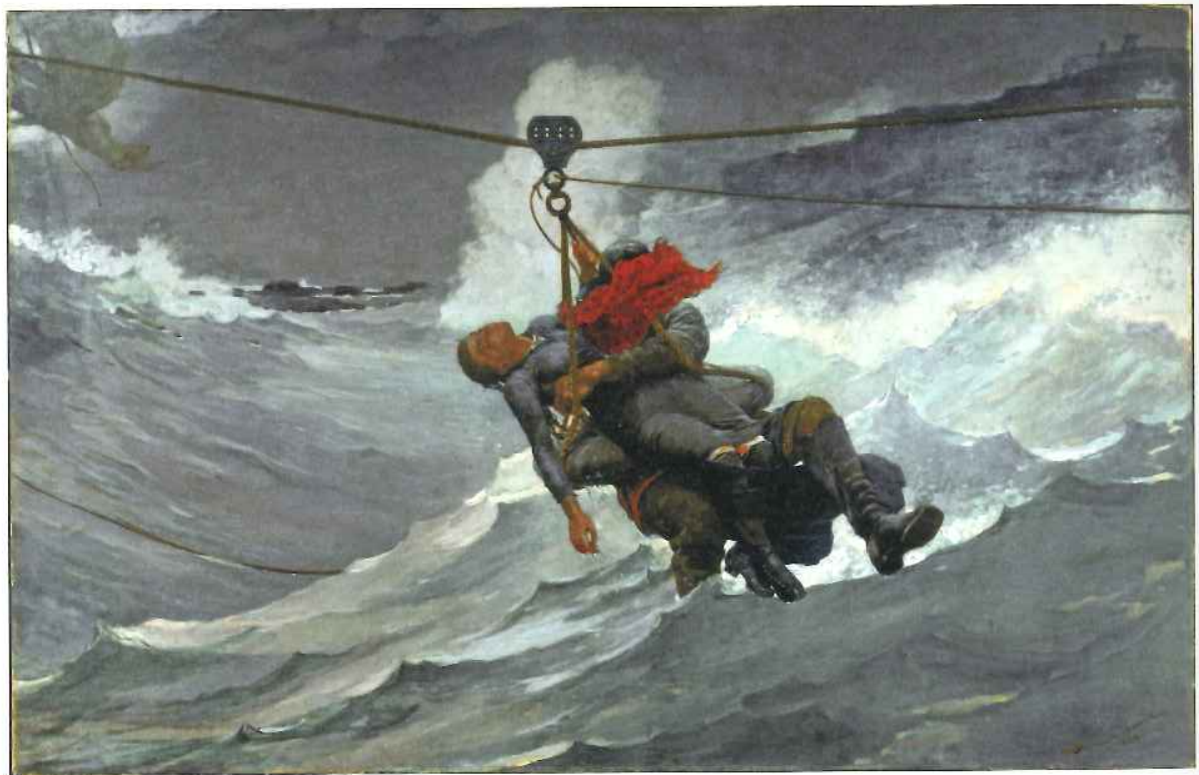

LXXXI Winslow Homer, The Life Line, 1884, Öl auf Leinwand, 72,7×113,7 cm,

Philadelphia Museum of Art 